\title{
Development of Low-Emission Integrated Steelmaking Process
}

\author{
Sharif Jahanshahi · John G. Mathieson - Michael A. Somerville \\ Nawshad Haque $\cdot$ Terry E. Norgate $\cdot$ Alex Deev $\cdot$ Yuhua Pan • \\ Donsheng Xie $\cdot$ Phillip Ridgeway $\cdot$ Paul Zulli
}

Published online: 5 February 2015

(C) The Minerals, Metals \& Materials Society (TMS) 2015

\begin{abstract}
This paper provides a summary of the progress made over the 8 years of an R\&D program that focused on the development of know-how and processes that could result in substantial reduction in net $\mathrm{CO}_{2}$ emission by the steel industry. The processes that were developed covered introduction of renewable carbon and energy sources as well as minimising waste heat from processes. The current status of each of the processes and application areas is provided. The use of biomass-derived fuels and reductants in the ironmaking and steelmaking industry provides a sustainable option for reducing net $\mathrm{CO}_{2}$ emissions at a lower capital cost and technological risk than other breakthrough technologies under development. A key focus of this program has been to partially substitute these fossil-based fuels with renewable carbon (charcoal) from sustainable sources such as plantations of biomass species or forest wastes. Raw biomass is unsuitable for applications in ironmaking and steelmaking and should be converted into charcoal (char) through a pyrolysis process before use. A new pyrolysis process which operates continuously and autogenously has been developed and
\end{abstract}

S. Jahanshahi $(\bowtie) \cdot$ J. G. Mathieson - M. A. Somerville ·

N. Haque - T. E. Norgate $\cdot$ A. Deev $~$ Y. Pan - D. Xie

CSIRO Mineral Resources Flagship, Clayton, VIC 3168, Australia

e-mail: sharif.jahanshahi@gmail.com

Present Address:

S. Jahanshahi

Meta-Logical Solutions, Armadale, VIC, Australia

P. Ridgeway

Arrium, Newcastle, NSW 2300, Australia

P. Zulli

BlueScope, Port Kembla, NSW 2505, Australia piloted. The biomass-derived chars and hydrocarbon fuels have great potential in lowering the net $\mathrm{CO}_{2}$ emissions of integrated (BF-BOF route) steel plants. Life cycle assessment has quantified the potential reduction in net $\mathrm{CO}_{2}$ emissions and covers cradle to gate, including plantation, harvesting, transport, pyrolysis and use of chars and bio-oil products. The properties of chars produced by biomass pyrolysis can be tailored to each of the several applications proposed (sintering solid fuel, cokemaking blend component, blast furnace tuyere injectant, liquid steel recarburiser, etc.), thus resulting in optimal performance and greater value-in-use of the char. Our economic analysis has made allowance for such value-in-use in applications, particularly as a replacement for BF pulverised coal injection. This analysis shows that key factors influencing the economics are the net cost of producing charcoal from biomass, selection of pyrolysis technology, value of the pyrolysis by-products, as well as the value-in-use for the charcoal. Dry slag granulation (DSG) has the potential to make a fundamental change in slag treatment and deliver a more sustainable alternative compared with the conventional water granulation process. The DSG process not only saves valuable water resources and reduces sulphurous emissions, but it may also recover a large amount of the high-grade heat in molten slag so to reduce greenhouse gas emission. CSIRO has been working on the development of a novel DSG process, integrated with heat recovery, since 2002 and has made significant progress in process design and optimisation based on process modelling, laboratory investigations, extensive pilot plant trials and characterisation of the solidified product granules.

Keywords Biomass - Charcoal · Pyrolysis - Ironmaking · Steelmaking · Techno-economics $\cdot$ Life cycle assessment . Dry slag granulation - Waste heat recovery 


\section{Introduction}

Our society is strongly dependent on the supply of cement, concrete and steel to the construction and transport industries. After cement, steel is the highest volume material produced by mankind, with global crude steel production exceeding $1.5 \mathrm{Gt}$ in 2013, [1]. The steel industry is a significant contributor to global $\mathrm{CO}_{2}$ emissions and the World Steel Association has indicated this to be $6.7 \%$ of total emissions, based on 2010 data [2]. The Scope 1 and Scope 2 emissions from the iron ore-based integrated steelmaking route, the blast furnace (BF) - basic oxygen furnace (BOF) route, are typically around $2 \mathrm{t}-\mathrm{CO}_{2} / \mathrm{t}$-crude steel, while those from the scrap-based electric arc furnace (EAF) route are dominated by emissions from electrical power generation $(85 \%)$, and are typically around $0.5 \mathrm{t}-\mathrm{CO}_{2} / \mathrm{t}$-crude steel where power is generated using black coal.

The steel industry has a large incentive to decrease energy usage and thereby reduce production costs, and is already very efficient, with advanced plants approaching theoretical minima [3]. However, in order to combat anthropogenic global warming, the international steel industry has accepted the challenge to cut net $\mathrm{CO}_{2}$ and other greenhouse gas (GHG) emissions by $50 \%$ or more by 2050 . Major programs have been underway for a decade. For example, the European Union has the Ultra-Low $\mathrm{CO}_{2}$ Steelmaking project [4-7]. Japan has its $\mathrm{CO}_{2}$ Ultimate Reduction in Steelmaking Process by Innovative Technology for Cool Earth 50 project [8-10] and also a series of other initiatives [10]. South Korea, North America and Australia [12,13] also have significant programs.

To date, most emphasis has been placed on the development of either, (a) innovative new ironmaking processes [14] or (b) major modifications to the BF, because it is the principal emitter. The new or modified processes either substitute $\mathrm{H}_{2}$ for $\mathrm{CO}$ as the reductant (producing $\mathrm{H}_{2} \mathrm{O}$ rather than $\mathrm{CO}_{2}$ in the evolved gases-note that $\mathrm{H}_{2} \mathrm{O}$ is a GHG!) or aim at producing very concentrated off-gas $\mathrm{CO}_{2}$ streams, suitable for carbon capture and storage (CCS) [5].

As an alternative, the use of biomass-derived renewable fuels as substitutes for non-renewable fuels (coal, coke, natural gas, oil) is also being investigated, particularly by researchers in Australia, Brazil, Canada and Europe. The utilisation of biomass-derived materials can be considered to be part of a continuous balanced cycle of (a) biomass growing and absorbing $\mathrm{CO}_{2}$ from the atmosphere, with storage of carbon as organic compounds, (b) harvesting and utilisation of the biomass (e.g. combustion of the stored carbon, emitting $\mathrm{CO}_{2}$ to the atmosphere) and (c) recycling of the $\mathrm{CO}_{2}$ back into storage as new growth. Cradle-to-gate life cycle assessment studies [15] indicate that provided the biomass is grown sustainably, e.g. in managed plantation forests, the production and utilisation of the biomassderived products is either near $\mathrm{CO}_{2}$ neutral or can even be negative in the case where the pyrolysis by-products are beneficially utilised.

The biomass option is attractive, not only because such fuels can be $\mathrm{CO}_{2}$ neutral, but also because existing ironmaking and steelmaking plants can be retained with little or no need for modification and capital expenditure. In addition, key aspects have already been pioneered in Brazil which has a significant ironmaking industry based on sustainably produced charcoal from eucalypt plantations.

Waste heat recovery from molten ironmaking and steelmaking slags could also provide an opportunity to further reduce the energy requirements and hence $\mathrm{CO}_{2}$ emissions by the industry. The potential saving in energy has been estimated to be significantly large (700-800 PJ per year) by the steel industry $[4,16]$. Like water granulation of slags, dry granulation could convert the vast quantity of BF slag produced globally ( $\sim 400 \mathrm{Mt} /$ year) into feedstock for cement and concrete production thus resulting in further reduction in the GHG emissions by the cement industry [17].

The Australian Steel Industry $\mathrm{CO}_{2}$ Breakthrough Program was initiated by BlueScope Steel in 2006, through collaboration with OneSteel/Arrium and CSIRO. This program aims to reduce net GHG emissions by the steel industry through use of renewable carbon sources as fuels and reductants, as well as the recovery and utilisation of waste heat from molten slags. The key research questions behind this program are as follows:

- Can deep cuts into $\mathrm{CO}_{2}$ emissions be made using current process equipment?

- Can charcoal provide a low-capital path to a low- $\mathrm{CO}_{2}$ future?

- Can waste heat recovery from molten slag provide a further cut in $\mathrm{CO}_{2}$ emissions?

- Can dry granulated BF slag be a good substitute for Portland cement?

The combination of (1) sustainable supply of biomass and its processing to produce charcoal, bio-oil and other renewable energy; (2) utilisation of charcoal as partial replacement for coal and coke products in ironmaking and steelmaking; (3) recovery of high-grade waste heat from molten slag and (4) conversion of molten BF slag into a Portland cement substitute has been defined as the lowemission integrated steelmaking process (ISP). In Fig. 1, the conceptual flowsheet for the ISP is presented.

\section{Biomass}

Supply of Biomass from Sustainable Sources

One of the questions that needed to be addressed was "do we have sufficient supply of biomass resources in the short and 


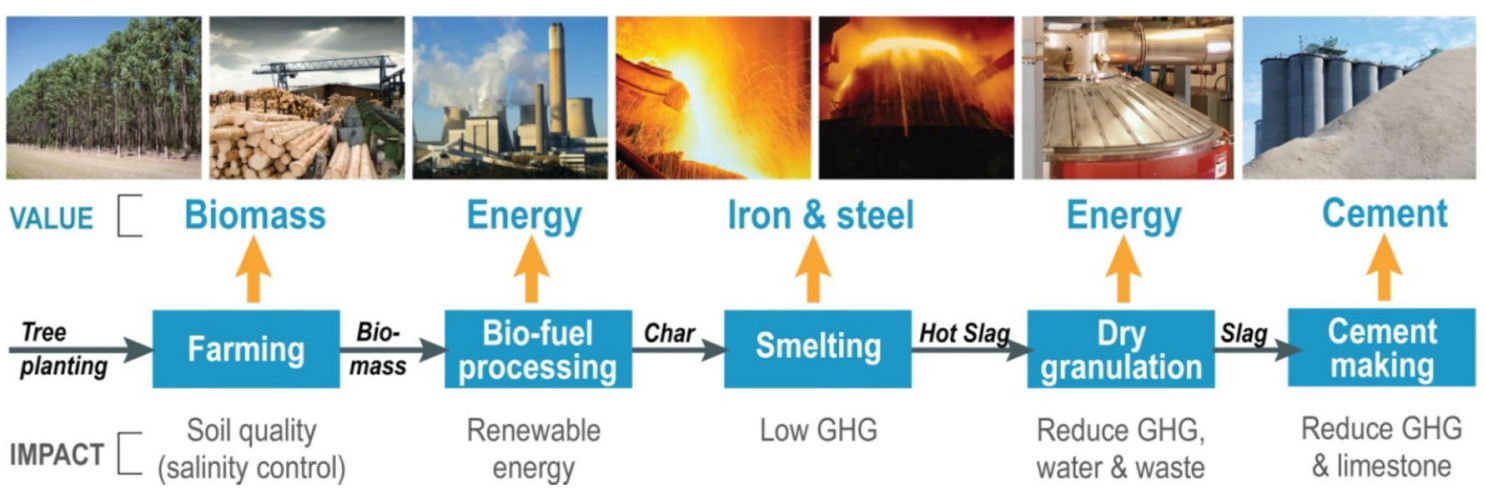

Fig. 1 The conceptual flowsheet across the value chain for the low-emission integrated steelmaking process (ISP)

medium terms to support the steel industry in Australia?" To address this and related questions, a survey of existing resources and residues available from plantations in suitable regions of Australia was carried out. The quantities of biomass available from Northern, Central, Southern New South Wales, Western Victoria and Southern South Australia were estimated by Haque et al. [18]. These regions were selected due to their proximity to the existing local steel plants and to plantation forests. This estimate was based on information gathered through site visits, meetings with the state forestry agencies, wood processing industries, and where possible, from the open literature.

The annual forestry (in-forest) and wood processing (e.g. sawmill) residues in Australia were estimated on an oven-dry basis to be 3.4 and $2.3 \mathrm{Mt}$, respectively. Non-forestry residues were estimated to be around $1.7 \mathrm{Mt} / \mathrm{year}$ and included biomass from grain crops such as wheat and maize, olive pomace, grape marc, almond waste and cut flower waste. A significant part of non-forestry waste was from sugarcane bagasse, in-field cane crop residues, woody weeds (Camphor Laurel) and macadamia nut processing waste in northern New South Wales. Assuming $30 \%$ charcoal yield from dry residues, and that $50 \%$ of total dry residues were available immediately, this leads to $3.7 \mathrm{Mt} /$ year of dry biomass that can potentially generate about $1.1 \mathrm{Mt}$ of charcoal per year.

These results indicate that currently the biomass residues from forestry and agricultural industries are sufficient to satisfy the short-to-medium term needs of the Australian steel industry (5-10 years). In the longer term (10-15 years), some dedicated plantations of short rotation biomass species would have to be planted with a growth development time of around 7-8 years to ensure a secure supply of biomass material from sustainable sources.

Key Requirements for Biomass-Derived Fuels and Reductants for the Steel Industry

Raw biomass, whether from trees, grasses or algae, cannot be directly substituted for the conventional fossil-based fuels used in ironmaking because of its high moisture content, low carbon content and low calorific value (CV) [19]. Pyrolysis (thermal decomposition in the absence of oxygen) is required to produce carbon-rich chars. Wood is the most commonly used form of biomass and the resultant chars are named according to the degree of pyrolysis, e.g. torrefied wood (produced at ca. $300{ }^{\circ} \mathrm{C}$ ), semi-charcoal (produced at ca. $400{ }^{\circ} \mathrm{C}$ ) and various charcoal types (produced from 500 to $800{ }^{\circ} \mathrm{C}$ ).

In general, the objective is to make the biomass-derived chars both chemically and physically similar to their conventional counterparts, i.e. coal, coke and coal-based chars. Theoretically, it may be possible to produce enhanced replicas of each of the conventional materials from biomass, but costs also need to be competitive. In practice, chemical similarity is relatively easy to achieve, but comparable physical properties such as density, mechanical strength and reactivity may require prohibitive amounts of processing. It is usually conceded that a replica with the mechanical strength and structure of BF lump coke is currently unattainable at reasonable cost.

Although the need for processing raw biomass adds costs, three factors act in favour of biomass-derived chars. First, they normally have excellent chemical properties, i.e. low ash, sulphur and phosphorus contents. Second, by pyrolysing at various temperatures from around 450 to $800{ }^{\circ} \mathrm{C}$, key properties can be tailored to optimise use in each application, e.g. volatile matter (VM) and CV. Last, the cost of processing can be partially offset if the pyrolysis co-products (bio-oil, combustible gases and chemicals) are captured, processed and sold or directly utilised. As mentioned above, achieving competitive cost structures for the manufacture of various charcoal types is a key requirement for biomass-based fuels and reductants to be utilised.

Life Cycle Assessment of Biomass and Charcoal Supply for the Australian Steel Industry

The next question that arises is whether the biomass/ charcoal option is environmentally and economically 
sound. To address this, life cycle assessments (LCA) were carried out covering both environmental and economic dimensions.

LCA methodology was used to estimate the GHG footprint of charcoal production from Mallee eucalypt biomass, and is described in detail elsewhere [15]. The results of this LCA, showing the contributions or global warming potential (GWP) of the various stages to the GHG footprint of charcoal production, are shown in Fig. 2.

The GHG footprint for charcoal production was $105 \mathrm{~kg}$ $\mathrm{CO}_{2}$-e/t-charcoal, which reflects the fossil fuel used in its production (i.e. plantation management including fertilizer, harvesting and transport). Since the charcoal plant, which includes drying and pyrolysis of biomass, can be fuelled entirely by combustion of biomass by-products with modern efficient technology design, any emissions associated with these stages are in this scenario not fossil fuel based.

GHG credits for the bio-oil and combustible bio-gas byproducts produced during charcoal production (i.e. electricity generated using the gas replaces electricity generated from black coal, and bio-oil replaces diesel) can significantly reduce the GHG impact. It is worth noting that the credits will normally outweigh the $105 \mathrm{~kg} / \mathrm{t}$-charcoal, meaning overall GWP is expected to be negative. However, it should be appreciated that the magnitude of the byproduct credits depends on the by-product yields in the charcoal retort, which in turn are dependent on a number of factors, in particular, the nature of the pyrolysis process (fast or slow) and the biomass feed composition. Slow pyrolysis tends to maximise the charcoal yield, with less gas and bio-oil by-products produced, so by-product credits are less.

\section{Techno-economic Evaluation of a Charcoal Plant}

Prior to commencing work on the pyrolysis process and techno-economics of charcoal production, an extensive review of the existing pyrolysis technologies was carried

\section{GWP (kg CO${ }_{2} \mathrm{e} / \mathrm{t}$ charcoal)}

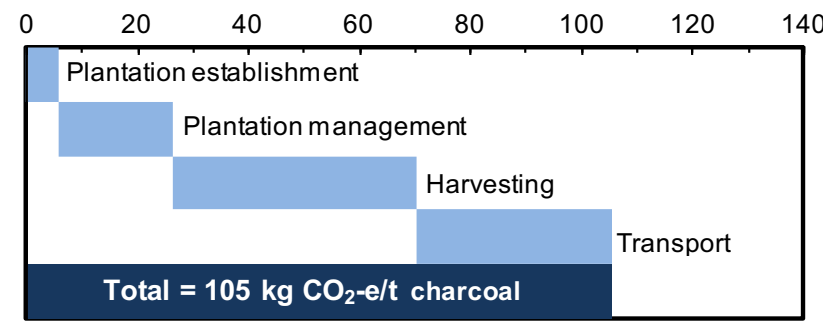

Fig. 2 Stage contributions to global warming potential (GWP) or greenhouse gas footprint of charcoal production (no by-product credits) out by Fung [20]. This review identified some of the key issues and shortcomings of existing technologies, which included low charcoal yield, non-recovery of by-products, in some cases low productivity due to batch-type operation, energy inefficiency, etc. These findings together with the techno-economic evaluation highlighted the need for development of a new pyrolysis process which addresses the deficiencies of the existing technologies.

It should be noted that the techno-economic evaluation presented here is based on the information gathered from the literature on existing commercial processes rather than what has been proposed in the following section of this paper.

Our initial techno-economic evaluation was carried out on a hypothetical charcoal plant situated in the state of New South Wales ( $\sim 300 \mathrm{~km}$ from steel plants located on the coast) with an annual capacity of 100,000 $t$ of charcoal (Fig. 3). In this scenario, woody biomass of mixed shape and size is transported from a nearby forest into a storage shed or bin. From there it is conveyed to a hopper. Raw feed materials are broken into chips by a chipping unit. The chipper produces particles of generally uniform size within a specified acceptable range. Some classification and sorting of particles is required at this stage.

The wet chips at around $50 \%$ moisture content (MC (dry basis)) are conveyed to a bed dryer unit. The operating temperature of the hot air over the drying bed is expected to be around $90{ }^{\circ} \mathrm{C}$ at $10 \%$ relative humidity. The hot air passes through the horizontally, slowly moving bed through perforated bottom plates. The nearly saturated moist air is exhausted by axial fans and is assumed to be $72{ }^{\circ} \mathrm{C}$ at $96 \%$ relative humidity. The as-received chips are dried to about $12 \% \mathrm{MC}$ (dry basis). It is assumed that the hot dry air for drying will be available as low grade waste heat from the pyrolysis unit.

The dry biomass chips are fed to the pyrolysis unit. Some of the combustible gases generated from pyrolysis of biomass are burnt to run the process. The remaining water in the biomass exits from the unit as vapour. The remaining gases are condensed to form bio-oil. The main product for this analysis is charcoal, which is discharged from the bottom of the pyrolysis unit.

The assumption is that the plant will produce charcoal suitable for BF injection as blend material with coal, or possibly other applications. The bio-oil produced can either be used on-site or supplied to other processes as thermal fuel.

In this analysis, the collection of pyrolysis condensate is included. The condensate is assumed to contain $20 \%$ organic fractions, as was found from earlier laboratorybased experiments [21]. The energy value of this organic fraction is assumed to be $50 \%$ of crude oil. All associated units for feed preparation, charcoal-making and bio-oil 


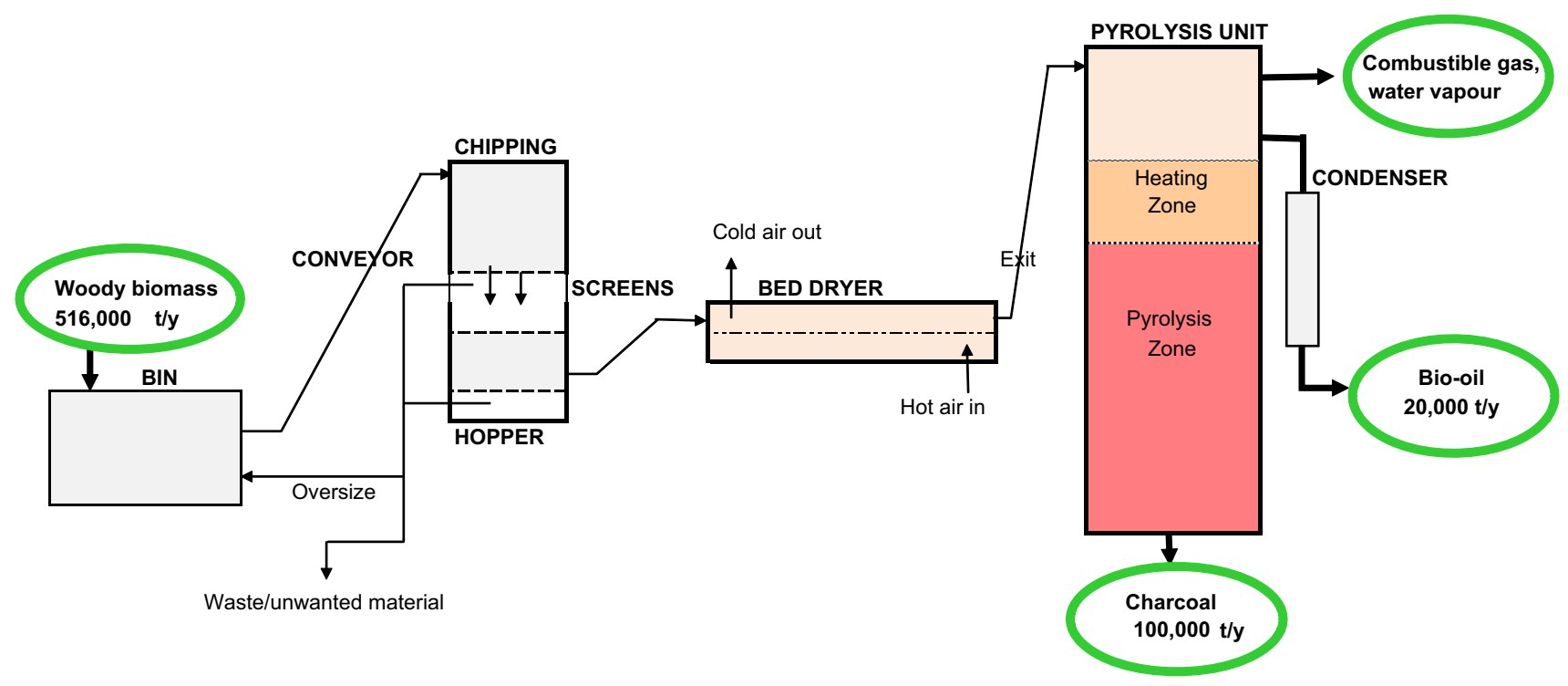

Fig. 3 Conceptual flowsheet of a 100,000 t/year charcoal plant

condensation are included in this economic analysis. The bio-oil condensate can be refined through further processing, the analysis of which is outside the scope of this study.

For this exercise, a process flowsheet was developed and the costs of key items of equipment were collected from various sources. The cost of the pyrolysis reactor was based on the technology described by Emrich [22] and Stuckley [23]. The estimated total capital cost was about AU \$111 M for this $100,000 \mathrm{t} / \mathrm{year}$ charcoal plant. The distribution of capital cost is shown in Fig. 4.

The required raw material feed and final charcoal product output rates were estimated based on the flowsheet and product yields obtained from a pilot-scale slow pyrolysis unit developed for biomass at CSIRO [24] ( $\sim 0.3 \mathrm{t}$ charcoal and $0.3 \mathrm{t}$ of condensate per $\mathrm{t}$ of oven-dry biomass, with about $20 \%$ of the condensate being bio-oil or $0.06 \mathrm{t}$ bio-oil).

The parametric evaluation was based on the scenario that

- The hypothetical charcoal plant is located at or near a saw mill and the product charcoal is transported to a steel plant ( $\sim 300 \mathrm{~km}$ away).

- Raw biomass is collected, chipped and dried close to the biomass source and transported $150 \mathrm{~km}$ to the sawmill and charcoal plant.

- The average cost of wet biomass (at approximately $50 \%$ moisture content) delivered to the charcoal plant is $\mathrm{AU} \$ 60 / \mathrm{t}$.

- The bio-oil product has a value of AU\$438/t (July 2014 price of crude oil in Australian dollars, (\$113/barrel) and the energy content of bio-oil is $50 \%$ of crude oil. It should be noted that if the diesel price is used, the value of bio-oil will increase two-fold.
- The net yield of bio-oil is $20000 \mathrm{t}$ (6\% of biomass).

The value-in-use ${ }^{1}$ of charcoal as an injectant into the $\mathrm{BF}$ is determined to be AU $\$ 116 / \mathrm{t}$ higher than a standard Hunter Valley PCI coal [13].

A carbon credit may be applied to the charcoal and byproducts such as bio-oil.

The net cost of charcoal from this plant was estimated to be AU\$243/t (Fig. 5), with value-in-use ( AU $\$ 116 / \mathrm{t}$ charcoal) and the value obtained from bio-oil ( $\sim$ AU $\$ 87 / \mathrm{t}$ charcoal) being considered. It is worth mentioning that $45 \%$ of the total operating cost of AU $\$ 446 / t$ at the charcoal plant was for supply of raw materials and $16 \%$ for transport. Maintenance and interest on capital, labour and utilities accounted for the remaining $39 \%$ of the cost.

It should be emphasised that making charcoal and supplying it to the iron and steel plant is financially viable if all the by-product credits and benefits are taken into account. However, introduction of carbon pricing for both bio-oil and charcoal will enhance the financial viability of charcoal iron (i.e. this net cost of AU $\$ 243 / \mathrm{t}$ would be considerably lower).

The techno-economic modelling has also shown that for a notional carbon price of $\$ 10 / \mathrm{CO}_{2}$-e, the credit for the bio-oil and charcoal would add up to about $\$ 43 / \mathrm{t}$ charcoal, making the net cost of charcoal $\$ 200 /$ t. This cost is greater than the price of PCI coal at the end of 2014. Thus, for a viable low net emission option under current circumstances, either the carbon price needs to be higher than $\$ 10$,

\footnotetext{
1 The value-in-use (VIU) is the "rational purchase price" (\$/t) for a test injectant, such that hot metal cost remains constant when the test injectant is used in place of a reference injectant.
} 
Fig. 4 Breakdown of estimated capital cost (total AU $\$ 111 \mathrm{M}$ for $100,000 \mathrm{t} /$ year at year 2014)

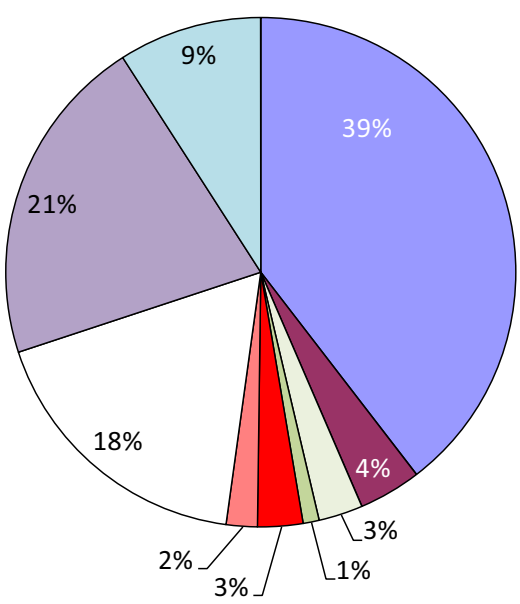

$\square$ Pyrolysis unit

$\square$ Drying unit

$\square$ Weighbridge, chipping \& screening

$\square$ Bins \& conveyor system

$\square$ Bio-oil extraction equipment

$\square$ Miscellaneous equipment

$\square$ Storage, handling, utilities, services

$\square$ Engineering, procurement \& construction management

$\square$ Contingency
Fig. 5 Cost and revenue from various key items per tonne of charcoal, for production of charcoal and bio-oil from raw biomass

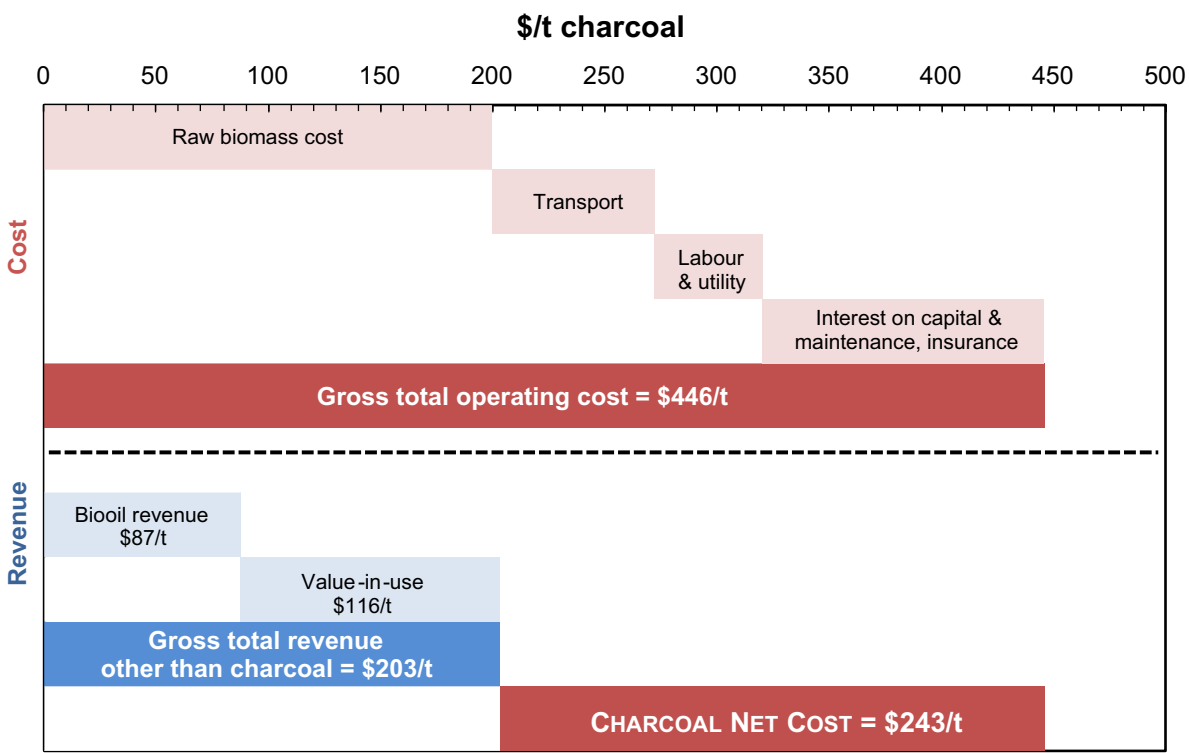

or the production cost of charcoal has to be reduced through reduced raw materials, capital or operating costs.

\section{Development of an Energy and Resource Efficient} Pyrolysis Process

The optimum substitution of charcoal for coal-based materials used for ironmaking and steelmaking imposes a number of requirements, such as acceptable price, density, VM and ash contents (see Table 1). Furthermore, even at moderate levels of replacement, millions of tonnes of charcoal are needed annually for a large integrated ironmaking and steelmaking plant. Existing charcoal-making technologies cannot satisfy the requirements for the quality of the product, its net price and the high production volumes [25]. Hence, the development of a new technology is needed. The ability to convert smaller-sized wood (such as wood chips or wood pellets) to charcoal should be an important feature of this new technology, as it permits the utilisation of lower-cost materials (wood waste/residues) and densified wood pellets as feedstock. Charcoal made from wood pellets (extruded wood) has up to three times higher density than that of conventional charcoal, which is essential for some applications (Table 2). An important contribution to the economic viability of charcoal-making is maximising the value from the by-products, namely pyrolysis condensate (also called bio-oil) and pyrolysis gas (syngas).

The main barrier to processing large volumes of smallsized wood in a pyrolysis reactor is the combination of low gas permeability of such material and its low thermal conductivity. The former makes heating by flow of hot gas impracticable and the latter diminishes the efficiency of external heating of the reactor. These difficulties can be 
Table 1 Charcoal properties for ironmaking (blast furnace and sintering) applications

\begin{tabular}{|c|c|c|}
\hline Charcoal property & Advantages & Disadvantages \\
\hline Low ash & Generally provides higher value products & \\
\hline Ash composition & $\mathrm{CaO}$ content may save on additional fluxes & $\begin{array}{l}\text { If biomass is grown in saline soil, alkalis (reported as } \mathrm{K}_{2} \mathrm{O} \text { and } \\
\mathrm{Na}_{2} \mathrm{O} \text { ) } \\
\text { may approach } \mathrm{BF} \text { limits in rare circumstances, requiring selective } \\
\text { sourcing or blending for } \mathrm{BF} \text { tuyere injection }\end{array}$ \\
\hline Controlled VM & $\begin{array}{l}\text { Flexibility. Allows graded properties, } \\
\text { simulating } \\
\text { coal types and coke }\end{array}$ & \\
\hline High combustibility & $\begin{array}{l}\text { Greater than coal for the same VM content, i.e. } \\
\text { improved heat balance as a BF injectant }\end{array}$ & $\begin{array}{l}\text { May be too high for full coke breeze substitution in sintering } \\
\text { without modification (densification) } \\
\text { Some propensity for spontaneous combustion of fines during } \\
\text { storage, requiring safeguards. }\end{array}$ \\
\hline High reactivity to $\mathrm{CO}_{2}$ & $\begin{array}{l}\text { Greater than coke in BF shaft, permitting } \\
\text { lower } \\
\text { temperature of thermal reserve zone (TRZ) }\end{array}$ & $\begin{array}{l}\text { May lead to poorer coke strength for BF if percentage in coke } \\
\text { making coal blend is above a threshold }\end{array}$ \\
\hline $\begin{array}{l}\text { Low mechanical } \\
\text { strength }\end{array}$ & Easier to grind for some applications & Unsuitable as a full substitute for top-charged coke in large BFs \\
\hline Low density & & Higher volumes for transport and manual handling \\
\hline $\begin{array}{l}\text { High moisture } \\
\text { adsorption }\end{array}$ & & $\begin{array}{l}\text { May require protection for some applications, e.g. storage } \\
\text { in air-tight bags. Difficult to dry if saturated }\end{array}$ \\
\hline Contamination & & $\begin{array}{l}\text { High surface area and porosity promote contamination of charcoal } \\
\text { fines by incidental contacts with dust and soil, requiring } \\
\text { precautions }\end{array}$ \\
\hline
\end{tabular}

Table 2 LCA-based total potential reduction in greenhouse gas emissions resulting from substitution of coal/coke with charcoal for different steelmaking routes (liquid steel basis)

\begin{tabular}{lll}
\hline $\begin{array}{l}\text { Steelmaking } \\
\text { route }\end{array}$ & $\begin{array}{l}\text { Total potential reduction } \\
\text { without by-product } \\
\text { credits }\left(\mathrm{t} \mathrm{CO}_{2} \text {-e/t steel }\right)\end{array}$ & $\begin{array}{l}\text { Total potential reduction } \\
\text { with by-product credits } \\
\left(\mathrm{t} \mathrm{CO}_{2} \text {-e/t steel }\right)\end{array}$ \\
\hline $\begin{array}{l}\text { Integrated } \\
\text { BF-BOF }\end{array}$ & $0.69-1.21$ & $0.91-1.61$ \\
$\begin{array}{c}\text { EAF mini- } \\
\text { mill }\end{array}$ & $0.028-0.056$ & $0.037-0.075$ \\
& $0.34-1.70$ & $0.45-2.15$ \\
\hline
\end{tabular}

overcome if autogenous pyrolysis is used. The process can be arranged so that the material is heated to the maximum pyrolysis temperature spontaneously by the heat of internal exothermic reactions, which occur within the material even without any air supply to the reactor [26]. A pilot-scale plant has been developed at CSIRO (see Fig. 6b) based on this principle. The flow diagram in Fig. 6a shows the main units. The vertical shaft reactor is well insulated, with wood charging equipment at the top and a charcoal discharging valve at the bottom. The simplicity of the mechanical design of the reactor, with no moving parts in its hot zone, ensures the minimisation of capital and maintenance costs. Additionally, cooling of charcoal in the bottom section of the reactor can be accelerated by circulating a non-combustible gas through it, which also permits the recovery of heat [25]. The flow of the cooling gas is confined to the bottom section of the reactor and the gas does not permeate the material in the rest of the reactor. Other main units are the dryer, the screw conveyors to transfer wood chips or pellets to the top of the reactor, condensers to capture liquid by-products and the afterburner.

The advantages of this technology are as follows:

- High energy efficiency, as no high-grade heat is needed to bring wood to the maximum pyrolysis temperature under steady-state conditions (low-grade heat is still needed for drying the feed material);

- High-yield of charcoal from wood, due to favourable conditions in the reactor [24];

- High value of pyrolysis by-products, since:

- pyrolysis gas is not diluted by any inert gases or combustion products and

- the condensate is not diluted by free moisture from the charge (the material is supplied to the reactor dry)

- No heat transfer limitation due to scaling up the reactor to large sizes, as no supply of external heat to the material is needed; production of large tonnages of charcoal per year by a single reactor unit may be achievable.

A pyrolysis pilot plant (internal diameter of reactor $\sim 600 \mathrm{~mm}$, maximum depth of material bed in the reactor $\sim 2,700 \mathrm{~mm}$, and nominal productivity of $100 \mathrm{~kg} / \mathrm{h}$ of charcoal, if operated continuously) has been commissioned at CSIRO and has been used to demonstrate that 
Fig. 6 a Process flow diagram of the pilot plant based on the principle of autogenous pyrolysis of wood. b Pyrolysis pilot plant developed at CSIRO to demonstrate the autogenous feature and produce various products from biomass for characterisation

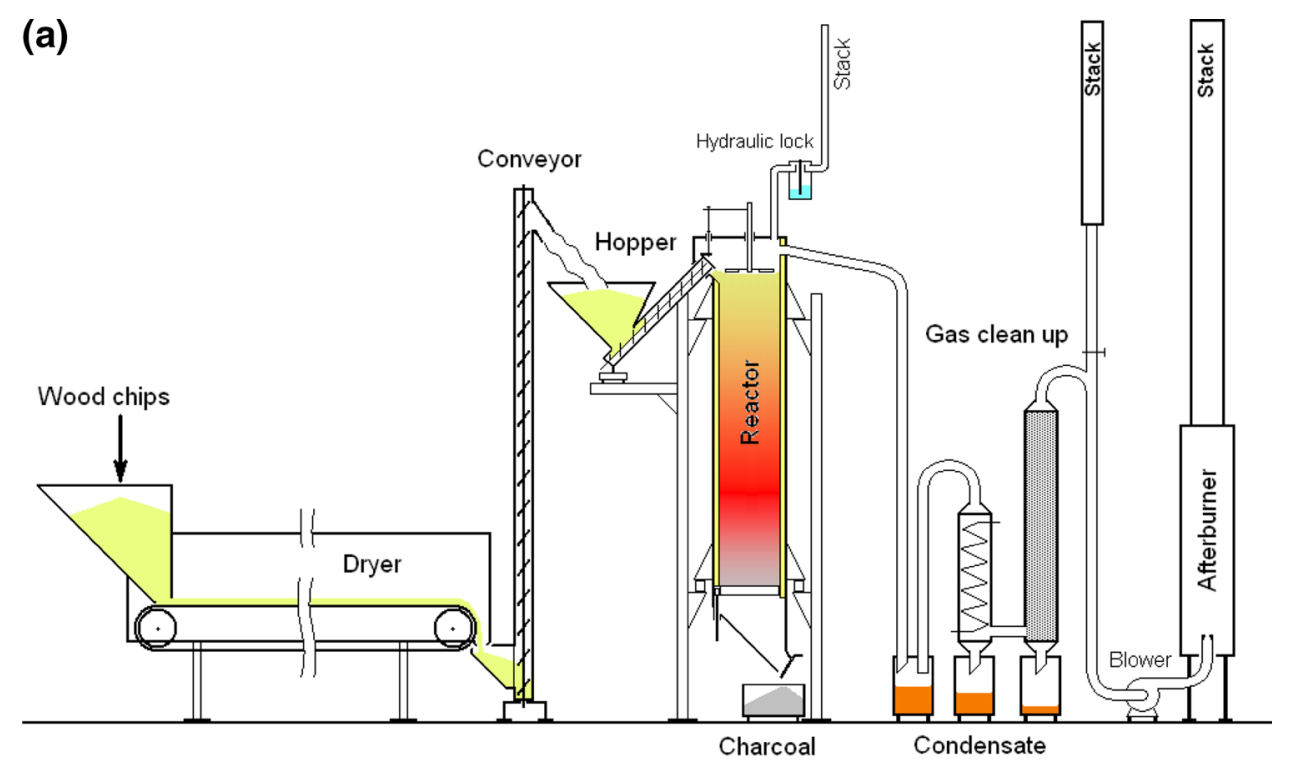

(b)

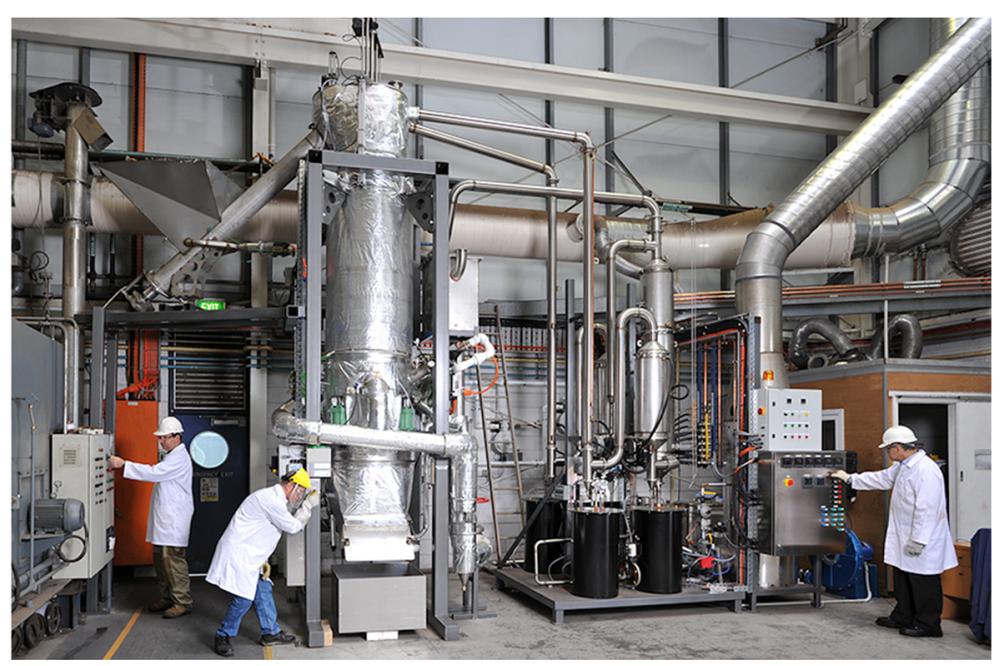

autogenous heating of the material can bring its temperature to $520{ }^{\circ} \mathrm{C}$.

A recent revised estimate of the capital cost by Koltun (2014, Private communication) has found that the capital cost of this technology is approximately $53 \%$ lower than that for the Lambiotte-type retort, due to its simpler equipment design and higher productivity (i.e. $75 \%$ reduction in residence time of material as compared to the Lambiotte-type retort that was studied in the preliminary evaluation as described in the previous section).

\section{Concept of Designer Chars for Various Applications} in Ironmaking and Steelmaking

As indicated previously, raw biomass is not suitable for ironmaking and steelmaking applications because of its high moisture content, low carbon content and low specific energy. Since pyrolysis is necessary to produce chars that are chemically similar to coal/coke, it is advantageous to produce optimised products that are either superior to traditional fuels/reductants or that minimise any weaknesses in physical properties.

The charcoal properties which are most relevant to ironmaking (BF and sintering) are shown in Table 1, along with how they may affect processing in an integrated steel plant, in comparison with conventional fuels and reductants.

The substitution of charcoal for coal/coke in ironmaking and steelmaking operations requires the preparation of charcoal with specific properties. Mathieson et al. [13, 2729] summarised the optimum quality criteria for charcoal substitution and showed that each application required different charcoal properties. For example, charcoal for sintering fuel should be of low-volatile content $(<3 \%)$, high density, low reactivity and in the $0.3-3 \mathrm{~mm}$ size range. In comparison, charcoal as a BF injectant should be 
higher in VM (10-20\%), low in ash and low in alkalis. Recent research conducted at CSIRO has focused on controlling the pyrolysis process to produce charcoal with the desired properties. This concept has been called "designer charcoal".

Table 1 indicates some factors to minimise charcoal's disadvantages. Charcoal's low density and high porosity adversely affect several areas, e.g. mechanical strength, combustibility in sintering, reactivity as a coking component, high moisture adsorption and ease of contamination. Processing options that can increase the density of charcoal include conducting the pyrolysis under compression or pyrolysing densified biomass, such as dense biomass fuel (DBF) pellets. Somerville et al. [30] showed that the VM content of charcoal can be controlled through the pyrolysis temperature (shown in Fig. 7a). Charcoal density can also be controlled through pyrolysis temperature as well as through the choice of biomass feedstock, i.e. dense wood (Fig. 7b). The use of DBF pellets as a pyrolysis feedstock has been found to be very effective in increasing the bulk density and particle density of charcoal. Densification of charcoal during and after pyrolysis has also been investigated. Similarly, alternative methods for controlling the ash content of the charcoal have been studied. These studies have shown selection of biomass species as well as different fractions of the plants can be used to produce charcoals with different ash contents and compositions. Other studies also suggest that apart from biomass type/ species, soil chemistry also affects the ash composition and content $[31,32]$.

Charcoal with low levels of moisture and VM (nondensified) has been prepared for successful steel recarburisation plant trials at Arrium's Sydney Steel Mill [33] i.e. an EAF steel plant. Dense charcoal has also been prepared and used for pilot-scale iron ore sintering trials [34].

\section{Life Cycle Assessment of Charcoal Substitution for Coal/Coke}

Norgate et al. [15] carried out LCA of the integrated, EAF mini-mill and direct smelting steelmaking routes with charcoal $(88.3 \% \mathrm{C}, 31.1 \mathrm{MJ} / \mathrm{kg}$, dry basis) substituted for coke, coal and carbon in various applications. For the integrated route, charcoal was assumed to replace coke ( $92 \% \mathrm{C}$, dry basis) and coal (75 \% C, dry basis) in the BF on an equivalent fixed carbon basis and pulverised coal injectant $(30 \mathrm{MJ} / \mathrm{kg})$ on an equivalent energy basis. In the direct smelting route, charcoal was assumed to replace coal (81.3\% C, dry basis) in the bath smelting reactor on an equivalent fixed carbon basis over a range of substitution rates up to $100 \%$. For the mini-mill/EAF route, charcoal was assumed to fully replace charge, injectant and recarburiser carbon $(85 \% \mathrm{C})$ on an equivalent fixed carbon basis. The results of these LCAs in terms of the total potential reduction in net GHG emissions from charcoal use, compared to the coal/coke base case values for the three steelmaking routes are listed in Table 2.

In terms of GHG emissions, Fig. 8 shows the physical significance of the results for the integrated route (with sinter rather than pellets as feed). The various components contributing to the GWP of the integrated route are shown along with the reductions achieved from the use of charcoal for the case without any pyrolysis by-product credits. These results mean that without any by-product credits, the greenhouse intensity for a sinter-based integrated BF-BOF route is reduced from approximately $2.17 \mathrm{t} \mathrm{CO}_{2}$-e/t-crude steel to between 0.96 and $1.48 \mathrm{t} \mathrm{CO}_{2}$-e/t-crude steel over the range of charcoal substitution rates considered.

\section{Value of Using Charcoal as a Substitute for Coal} and Coke

Due to the low ash, sulphur and phosphorus levels, charcoal is generally chemically superior to coal-based fuels/ reductants. This means that optimised charcoal products (see Table 3) should lead to fuel and other savings in ironmaking and steelmaking processes, as well as the advantages in using renewable carbon to combat net $\mathrm{CO}_{2}$ emissions. These advantages mean that designer charcoal products may have greater value than traditional fuels/ reductants in several applications. For example, Mathieson et al. $[13,27]$ estimated that the BF coke rate could be reduced by $23-30 \mathrm{~kg} / \mathrm{t}$ hot metal (HM) using charcoal as the tuyere injectant and $4.5-9 \mathrm{~kg} / \mathrm{t}-\mathrm{HM}$ by charging 5-10\% charcoal/ore composites. Our industrial trial [33] also indicated that charcoal was potentially a more efficient liquid steel recarburiser.

Mathieson et al. [13] illustrated the value-in-use (VIU) of various charcoal types compared with coal types for BF tuyere injection at $140 \mathrm{~kg} / \mathrm{t}-\mathrm{HM}$. It was also observed (see Fig. 9) that the three charcoal samples had calculated values $50 \%$ greater than the reference high-volatile bituminous coal, reflecting predicted lower BF coke rates and improved $\mathrm{HM}$ composition ( $\mathrm{Si}, \mathrm{S}$ and $\mathrm{P})$.

\section{Current Status and Future Directions of Designer Charcoal Applications}

Table 3 provides a summary of the charcoal applications proposed for ironmaking and steelmaking processes. Key quality parameters that optimise each application are given [29] as well as estimated net $\mathrm{CO}_{2}$ emissions savings based on simple substitutions [13] (gate-to-gate). Additional savings of around $50 \%$ in net emissions are indicated by cradle-to-gate LCA $[15,29]$, because it appears possible to 
Fig. 7 The effects of pyrolysis temperature on the a volatile matter content ( $\%$ dry basis) and b apparent density (particle density) of charcoal made from wood chips and dense biomass fuel (DBF) feedstocks (a)

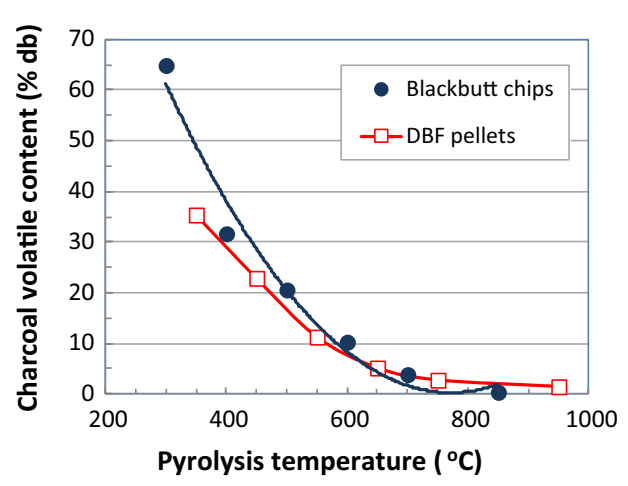

(b)

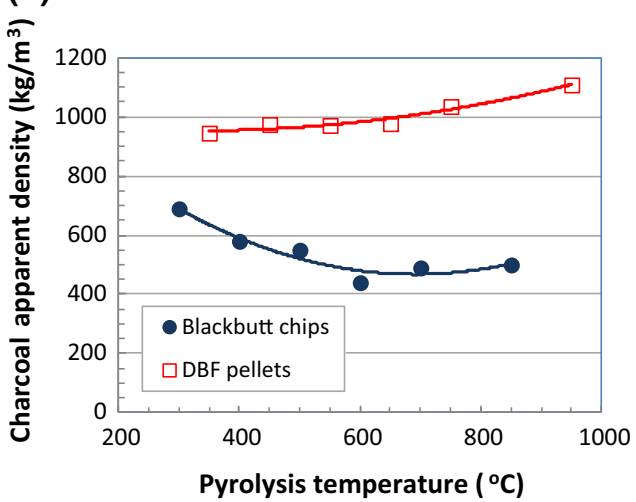

Fig. 8 Global warming potential (GWP) footprint of the integrated steelmaking route (sintering-BF-BOF) showing reduction with use of charcoal

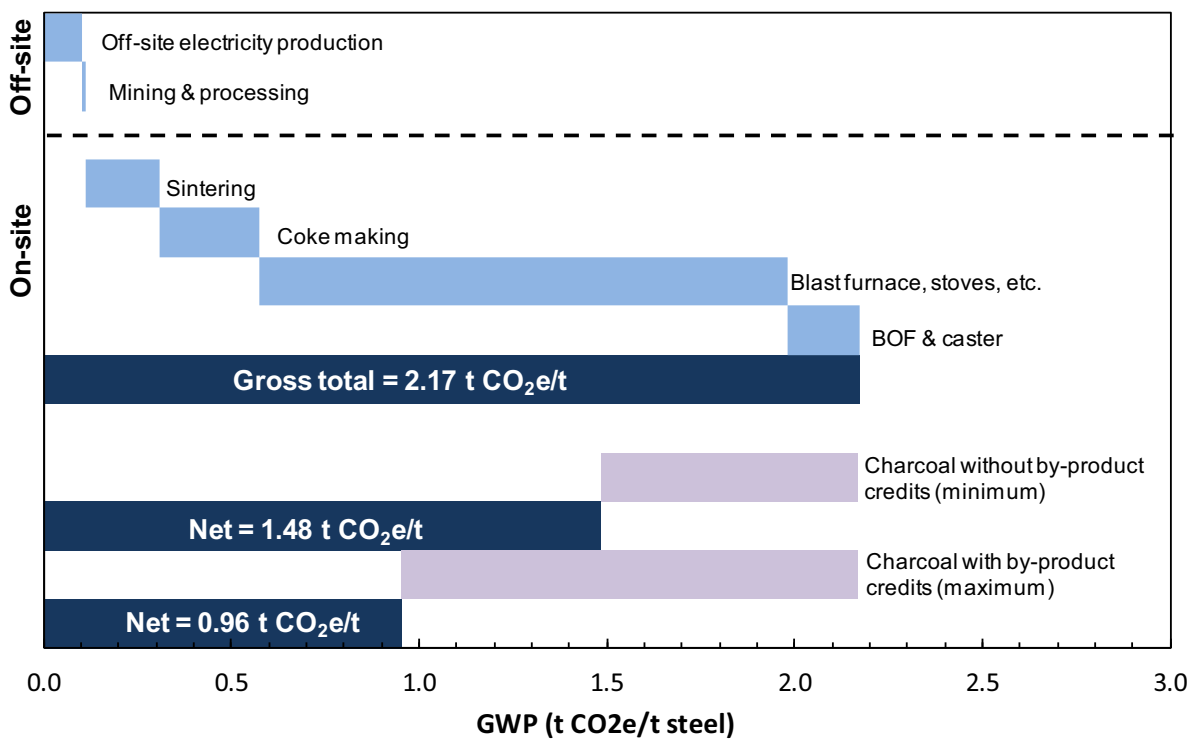

produce charcoal with negative GWP if pyrolysis co-products (bio-oil and combustible gases) are captured and utilised.

The aggregate $\mathrm{CO}_{2}$ emissions savings shown in Table 3 are calculated for Australian conditions and are 0.7-1.3 $\mathrm{t}-\mathrm{CO}_{2} / \mathrm{t}$-crude steel $(31-57 \%$ ) for the integrated BF-BOF steelmaking route, but only $0.04-0.06 \mathrm{t}-\mathrm{CO}_{2} / \mathrm{t}$-crude steel for the EAF route (8-12\%), because of the dominance of $\mathrm{CO}_{2}$ emitted for electricity generation in that sector. It will be observed that BF charcoal injection is the largest of the applications and has the potential to decrease net $\mathrm{CO}_{2}$ emissions by up to $25 \%$ in the integrated route. This application is already practiced at a rate of $100-200 \mathrm{~kg} /$ $\mathrm{t}-\mathrm{HM}$ in some Brazilian mini-BFs (up to $700 \mathrm{~m}^{3}$ inner volume).

With respect to the second largest of the applications, sintering, the pilot-scale tests conducted by CSIRO have shown that low volatile, or preferably dense, low-volatile charcoal, can successfully substitute for coke breeze, with higher productivity being possible, albeit at a slightly higher fuel rate [34]. Although full substitution may be possible, most integrated producers need to utilise indigenous coke breeze, so a more realistic limit for charcoal usage may be around $50 \%$ of the total solid sintering fuel.

As shown in Table 3 , the R\&D phase for several of the applications has been completed, hence making them ready for industrial trials or commercial operations.

\section{Dry Slag Granulation}

Dry slag granulation (DSG) could make a fundamental change in slag treatment. In this new approach, molten slag is atomised under centrifugal forces on a spinning disc, and the droplets generated are quenched and solidified quickly using air, with simultaneous heat recovery. The process produces solid slag granules suitable for use as a supplementary cementitious material (SCM) and hot air of 
Table 3 Charcoal applications proposed for ironmaking and steelmaking [12, 13]

\begin{tabular}{|c|c|c|c|c|}
\hline Application & $\begin{array}{l}\text { Optimised quality } \\
\text { parameters }^{\mathrm{a}}\end{array}$ & $\begin{array}{l}\text { Net } \mathrm{CO}_{2} \text { emissions } \\
\text { savings }\left(\mathrm{t}-\mathrm{CO}_{2} /\right. \\
\text { t-crude steel) }\end{array}$ & Current status & Next step \\
\hline Sintering solid fuel & $\begin{array}{l}\text { Low VM: }<3 \% \\
\text { High density }:>700 \mathrm{~kg} / \mathrm{m}^{3} \\
\text { Size: } 0.3-3 \mathrm{~mm}\end{array}$ & $0.12-0.31(5-15 \%)$ & Pilot-scale testing [34]. & Industrial trials \\
\hline $\begin{array}{l}\text { Cokemaking blend } \\
\text { component }\end{array}$ & $\begin{array}{l}\text { Low to mid VM: }<10 \% \\
\text { High density }{ }^{\mathrm{b}}:>700 \mathrm{~kg} / \mathrm{m}^{3} \\
\text { Size: }<1 \mathrm{~mm} \\
\text { Low alkalis }\end{array}$ & $0.02-0.11(1-5 \%)$ & $\begin{array}{l}\text { Bench-scale R\&D [54] and } \\
\text { pilot oven trials (Deev A } \\
\text { and Lu L (2014) Private } \\
\text { Communication) }\end{array}$ & Industrial trials \\
\hline BF lump charcoal charge & $\begin{array}{l}\text { Low to high VM: } 0-25 \% \\
\text { Higher strength } \\
\text { Size: } 30-60 \mathrm{~mm}\end{array}$ & $0.02-0.11(1-5 \%)$ & $\begin{array}{l}\text { Mini-BF commercial } \\
\text { operations [55] }\end{array}$ & $\begin{array}{l}\text { Proposed as minor } \\
\text { proportion of lump } \\
\text { coke charge R\&D }\end{array}$ \\
\hline BF nut coke replacement & $\begin{array}{l}\text { Low to mid VM: }<7 \% \\
\text { Higher density } \\
\text { Size: } 20-25 \mathrm{~mm}\end{array}$ & $0.08-0.16(3-7 \%)$ & $\begin{array}{r}\text { Mini-BF commercial } \\
\text { operations }[55,56]\end{array}$ & Trial on large BF \\
\hline $\begin{array}{l}\text { BF carbon/ore composites } \\
\text { (unreduced) }\end{array}$ & $\begin{array}{l}\text { Low VM: }<5 \% \\
\text { Size: } 80 \% \text { passing } 75 \mu \mathrm{m} \\
\text { High strength: }>500 \mathrm{~N}\end{array}$ & $0.08-0.15(3-7 \%)$ & Bench-scale R\&D [55] & RHF industrial trials \\
\hline BF pre-reduced feed & $\begin{array}{l}\text { High strength: }>500 \mathrm{~N} \\
\text { High metallisation: }>95 \%\end{array}$ & $0.09-0.18(4-8 \%)$ & Bench-scale R\&D [57] & Industrial trials \\
\hline BF tuyere injectant & $\begin{array}{l}\text { Higher VM: 10-20 \% } \\
\text { Low ash: }<5 \% \\
\text { Low alkalis }\end{array}$ & $\begin{array}{l}0.41-0.55 \\
\quad(19-25 \%)\end{array}$ & $\begin{array}{l}\text { Theoretical analysis [13] \& } \\
\text { combustion testing [28]; } \\
\text { Mini-BF commercial } \\
\text { operations }\end{array}$ & Trial on large $\mathrm{BF}$ \\
\hline $\begin{array}{l}\text { BOF pre-reduced feed } \\
\text { (scrap substitute) }\end{array}$ & $\begin{array}{l}\text { High strength: }>500 \mathrm{~N} \\
\text { High metallisation: }>95 \%\end{array}$ & $0.09-0.18(4-8 \%)$ & $\begin{array}{l}\text { Industrial practice with gas- } \\
\text { based DRI and HBI }\end{array}$ & Industrial trial \\
\hline BOF fuel (scrap melting) & $\begin{array}{l}\text { Low VM: }<3 \% \\
\text { Low moisture: }<2 \% \\
\text { High density }^{\mathrm{b}}:>500 \mathrm{~kg} / \mathrm{m}^{3}\end{array}$ & $\begin{array}{l}\text { Up to } 0.1(4.5 \%) \text {, } \\
\text { where employed }\end{array}$ & Untested & $\begin{array}{l}\text { Small-scale industrial } \\
\text { trial }\end{array}$ \\
\hline Liquid steel recarburiser & $\begin{array}{l}\text { Low VM: }<3 \% \\
\text { Low moisture: }<2 \% \\
\text { High density }^{\mathrm{b}}:>500 \mathrm{~kg} / \mathrm{m}^{3}\end{array}$ & $\begin{array}{l}0.001-0.004 \\
\quad(0.3-1.0 \%)\end{array}$ & Initial industrial trial [41] & $\begin{array}{l}\text { Extended Industrial trial } \\
\text { on optimised density } \\
\text { and commercial } \\
\text { operations }\end{array}$ \\
\hline EAF charge carbon & $\begin{array}{l}\text { Low to mid VM: }<7 \% \\
\text { Size: } 20-30 \mathrm{~mm} \\
\text { Low alkalis }\end{array}$ & $0.02-0.04(4-8 \%)^{\mathrm{c}}$ & Proposed & Industrial trial \\
\hline $\begin{array}{l}\text { EAF foaming agent/inject } \\
\text { carbon }\end{array}$ & $\begin{array}{l}\text { Low to mid VM: } 2-7 \% \\
\text { Moisture: } 1-7 \% \\
\text { Size: } 0.5-5 \mathrm{~mm} \\
\text { Low alkalis }\end{array}$ & $0.02(4 \%)^{\mathrm{c}}$ & Industrial trial [58] & $\begin{array}{l}\text { Industrial trial with } \\
\text { optimised charcoal }\end{array}$ \\
\hline
\end{tabular}

${ }^{a}$ Applications not requiring very low moisture levels require relatively dry charcoal, say $<12 \%$ moisture

b This is particle (not bulk) density, e.g. made from DBF pellets

${ }^{c}$ Refers to savings in an EAF plant

$500-600{ }^{\circ} \mathrm{C}$ as a potential heat source for on-site utilisation. Compared with water quenching, dry granulation offers a much more sustainable approach through saving water, reducing emissions, as well as recovering waste heat to reduce industry's energy consumption and hence GHG emission.
The concept of dry granulation was proposed more than 30 years ago and has since been the subject of numerous studies [35-40]. In these studies, molten slag was first broken up into small droplets by a number of mechanical means such as air blasting, rotary $\operatorname{drum}(\mathrm{s})$ and spinning disc/cup. The slag droplets were then quenched and 
Fig. 9 Calculated value-in-use (VIU) (relative to high-volatile coal A) for BF injectants (order of injectants: increasing VIU. Asterisk indicates injection at $60 \mathrm{~kg} / \mathrm{t}-\mathrm{HM}$, rather than $140 \mathrm{~kg} /$ $\mathrm{t}-\mathrm{HM})$. The VIU is the "rational purchase price" $(\$ / t)$ for a test injectant, such that hot metal cost remains constant when the test injectant is used in place of a reference injectant. $T W$ terrified wood, $S W$ soft wood, $H W$ for hard wood, $\mathrm{Hi}$-vol high-volatile matter

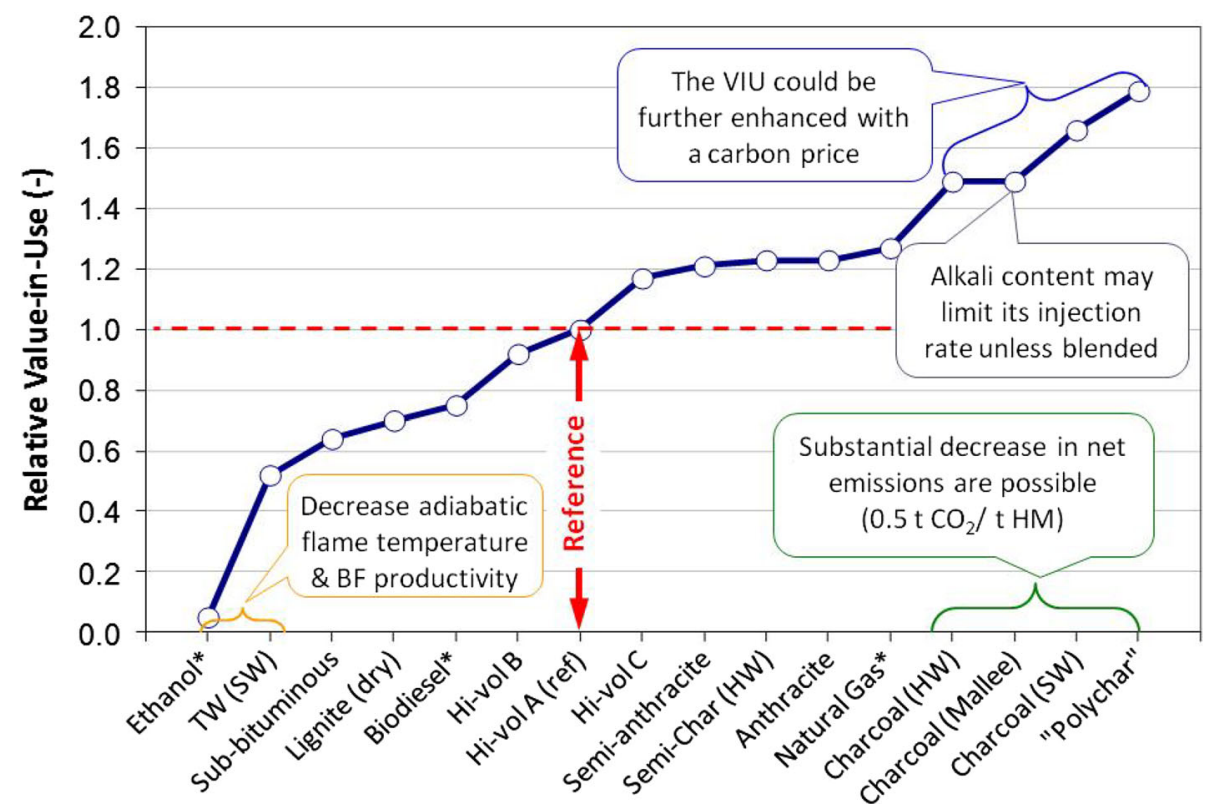

solidified using air. High-grade heat could be recovered by blowing air to extract heat from flying slag droplets or from solid granulates to produce hot air. The thermal energy in the hot air could then be converted to chemical energy (e.g. syngas) or electrical energy (e.g. thermoelectric power generation) [36]. In these studies and proposed processes, the sensible and latent heats were often recovered by air from molten slag droplets and hot granules mainly through convection and conduction. Some of these proposed processes were more extensively researched and tested, including air blast dry granulation trialled by Mitsubishi Heavy Industries in 1970-1980s [35, 38, 39] single drum dry granulation process by IHI and Sumitomo Metal Industries in the 1980s [35], spinning disc/cup dry granulation process proposed by Sumitomo Metal Industries and IHI in 1982 [40] and British Steel and the University of Nottingham in 1985 [38] and later by VAI UK [36, 37]. More recent publications by researchers from Europe [4143], Japan [44, 45] and China [46] indicate renewed interest in the area of slag heat recovery.

The merits and shortcomings of various approaches have been reviewed previously by Xie et al. [16] and more recently by Barati et al. [4] who focused on heat recovery only. In comparison with other methods, dry granulation using a spinning disc/cup offers a more efficient process for slag granulation [46], which uses less air than blasting with air to break up the slag into droplets, and thus has the potential to produce a higher-grade heat source for subsequent utilisation. However, the spinning disc/cup-based process has not as yet been commercialised due to some design difficulties, including appropriate disc design to avoid the formation of slag "wool" and effective granulator design to handle hot slag droplets and granules while avoiding sticking and agglomeration of hot slag particles.

CSIRO started working on DSG in 2002. Following an extensive investigation, major breakthroughs have been made to overcome the above-mentioned design difficulties. A novel disc design has been developed to produce fine granulates without slag wool. A cyclonic air flow is employed to efficiently quench the hot droplets/granules to produce a highly glassy product. These breakthroughs make it possible to significantly reduce the droplet flying distance, leading to a compact reactor design that can efficiently recover heat. An integrated dry granulation and heat recovery process has now been developed. In this paper, we will give an overview of some of the recent progress and current state of the development of the new dry granulation process.

\section{Overview of CSIRO DSG Process}

The CSIRO DSG process is based on a two-step operation involving a dry granulator and a moving bed counter-current heat exchanger as shown in Fig. 10 [47]. This conceptual design evolved from analysis of some focused experimental and process modelling studies. In this process, the "granulator" receives and atomises molten slag to produce droplets, which are quenched rapidly and solidified to become granules. The hot granules $\left(\sim 800{ }^{\circ} \mathrm{C}\right)$ are then fed to a second unit, a counter-current moving packed bed heat exchanger, where they are further cooled and finally discharged at close to ambient temperature. Air is used in both units to recover the heat and to produce hot air 
Fig. 10 Conceptual process flowsheet for integrated dry granulation and heat recovery [45]
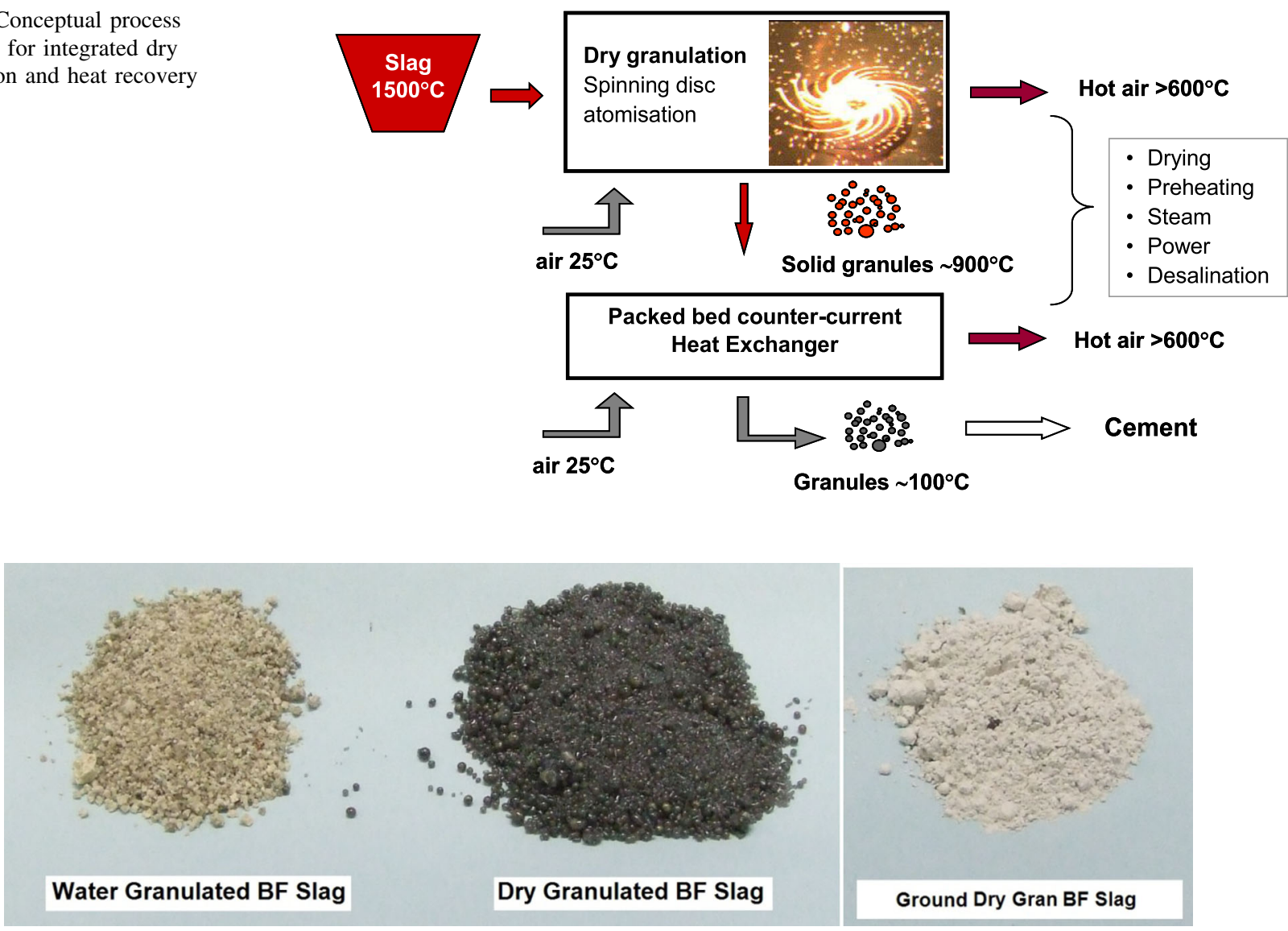

Fig. 11 Granules produced from wet and dry granulation processes [48]

with temperatures of $500-600{ }^{\circ} \mathrm{C}$. The two-unit operation allows simplification and decoupling of the key functions of each unit and hence enables maximising the recovery of high-grade heat (higher off-gas temperature). To achieve high-grade heat recovery, the volumetric air flow rate in the granulator must be minimised. For this purpose, a compact granulator was designed for intensive dry granulation which could produce an off-gas at $500-600{ }^{\circ} \mathrm{C}$ (based on the heat balance). The packed (moving) bed is employed to maximise heat recovery and discharge the final granules at lower temperature.

A prototype DSG pilot plant with a 1.2-m-diameter granulator (up to $10 \mathrm{~kg} / \mathrm{min}$, spinning disc up to $70 \mathrm{~mm}$ in diameter) was designed and built to prove the concept [47, 48] at CSIRO's Melbourne research laboratories. The granulated products produced by this prototype unit were mostly $(>90 \%)$ smaller than $1.5 \mathrm{~mm}$ in diameter. These granules were denser and appeared darker (Fig. 11) than water granulated slag, and their colour changed to light grey after grinding. The granulated products were highly glassy $(\sim 98 \%)$ and were found to have good cementitious properties, and hence suitable as an additive to Portland cement. Sulphur emissions as $\mathrm{H}_{2} \mathrm{~S}$ or $\mathrm{SO}_{2}$ during the dry granulation of re-melted BF slag containing 0.52-0.73 wt $\%$ $\mathrm{S}$ were found to be negligible. The off-gas from the unit passed through a drop-box to remove a small amount of dust, which was less than $0.2 \%$ of the product. It was found that the integrated process (spinning disc granulator and the moving packed bed) could be operated fully enclosed for recovery of hot air and containment of any gaseous emissions. More details of test results can be found in previous publications $[12,45]$.

The performance of this process with respect to heat recovery could not be fully tested in the laboratory-scale DSG trials due to the limitations imposed by the capacity of the slag melting furnace and hence short tapping time (1-2 min depending on tapping rate) which did not allow reaching steady-state conditions. However, some very promising results were obtained for these short tapping and granulation periods which are presented below.

The test work was focused on efficient air delivery to provide smooth operation at a given air flow rate and process integration from receiving molten slag to discharging solid granules at low temperature. Efficient air delivery to quickly cool the droplets is crucial for the smooth operation of a compact granulator and for the 


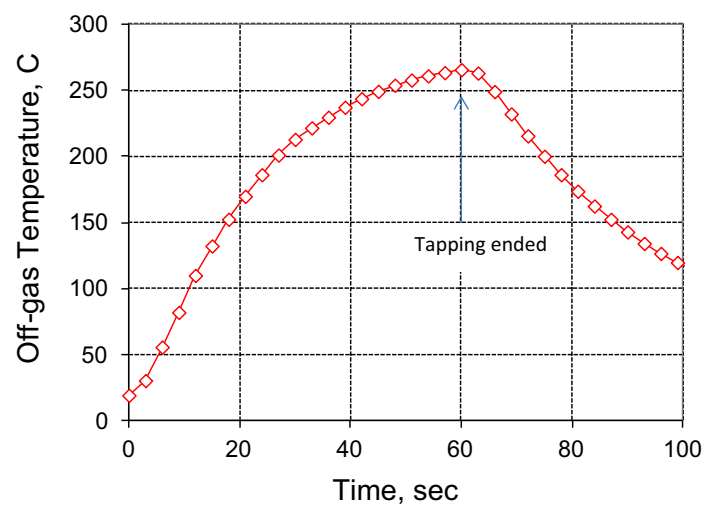

Fig. 12 Off-gas temperature measured as a function of time for the dry granulation of a blast furnace slag at $1,450{ }^{\circ} \mathrm{C}$ for a slag tapping rate of $7.6 \mathrm{~kg} / \mathrm{min}$ and air flow rate of $390 \mathrm{Nm}^{3} / \mathrm{h}$

performance of the heat recovery process. Thus, considerable efforts were directed towards resolving operational issues relating to the movement and fast cooling of granules using relatively low flow rates of air inside the granulator, without sticking and agglomeration occurring. These trials demonstrated that efficient operation could be achieved under relatively low air flow rates as required to produce off-gas at temperatures of $\geq 500{ }^{\circ} \mathrm{C}$. Figure 12 shows the off-gas temperature measured during a dry granulation run of a slag at $7.6 \mathrm{~kg} / \mathrm{min}$ which was operated at an air flow rate of $390 \mathrm{Nm}^{3} / \mathrm{h}$ (which is less than half of the air input to produce off-gas at $500{ }^{\circ} \mathrm{C}$ ). The rapid increase in the off-gas temperature when tapping started and the ability to operate the process at relatively low air input indicated an efficient air quenching and granule handling process inside the granulator. However, the full capability of the present process design in heat recovery needs to be further tested in future large scale plant trials where a sufficient quantity of molten slag is available to operate the unit with continuous slag tapping and granulation periods sufficient to reach a steady state.

Following the success of the prototype DSG pilot plant, the new process has recently been scaled up by an order of magnitude to a semi-industrial scale $(100 \mathrm{~kg} / \mathrm{min}$ of slag) in preparation for further scale up to industrial scale (1-2 t/ min slag). A large semi-industrial scale DSG pilot plant with a 3-m-diameter granulator (with spinning disc of up to $250 \mathrm{~mm}$ in diameter and slag tapping rates up to $100 \mathrm{~kg} /$ min) has been designed, built and commissioned at CSIRO's Clayton Laboratory (Fig. 13). The new facility is being used to validate a computer model of the process, further optimise the process design, and gain first-hand experience with large DSG operations. Preliminary test results have been very encouraging with respect to validating the process model and confirming the feasibility of the process design for future scale up.

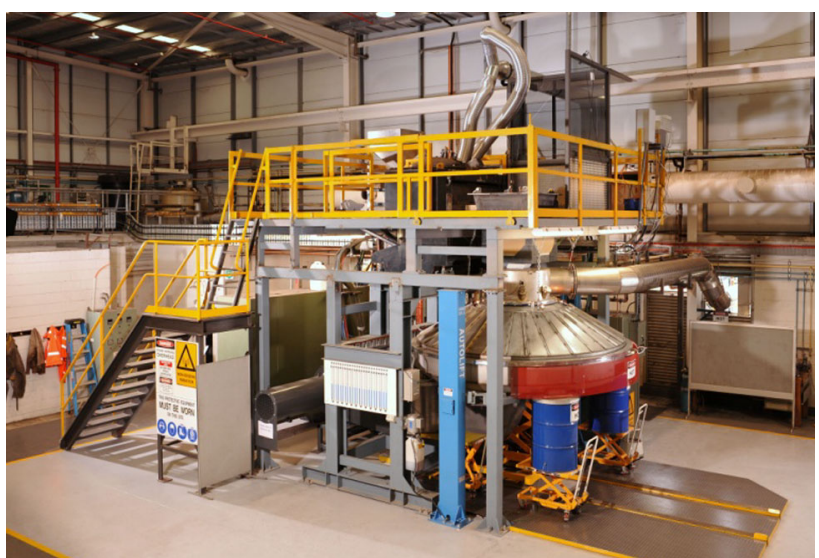

Fig. 13 The semi-industrial scale ( $3 \mathrm{~m}$ in diameter) integrated heat recovery and dry granulation pilot plant at CSIRO with design throughput of $6 \mathrm{t} / \mathrm{h}$ of slag [52]

DSG involves melt flow, droplet forming, and solidification in a complex and dynamic process. Slag properties and phase transformation under non-equilibrium conditions outside the normal operating temperature range play a central role in the process design and operation. Optimal disc atomization to suppress slag wool formation and appropriate handling of hot slag droplets/granules are the two most important fundamental issues to the success of dry granulation processes.

The design of the spinning disc involves disc material selection, disc cooling, as well as disc profile to provide optimal flow and atomization so as to produce fine droplets without formation of slag wool. Slag wool is often produced at the edge of the spinning disc when the ligament breakup to form slag droplets goes astray due to a number of possible reasons. Two of the necessary conditions to promote the formation of slag wool are (1) sufficient fast tearing of molten slag and (2) relatively low slag temperature and/or high slag viscosity. While it is difficult to quantify the exact conditions for the onset of wool formation, the experience gained over the years indicates that the slag wool formation often occurs when either the slag temperature is too low or disc spinning rate is too high for a given set of operating conditions (e.g. slag tapping rate, disc design and cooling).

A novel disc design is employed in the new CSIRO process based on a water cooled metal disc and optimised disc profile design to suit the scale of operation. The basis of the design is to form a solidified slag layer at the disc surface which not only protects the disc from direct contact with and possible attack by the slag, but also acts as a stationary insulation layer to reduce heat transfer from the slag to the metal disc. This helps to protect the metal disc from overheating and to avoid overcooling of the slag film (which could become very thin at high spinning rates) 


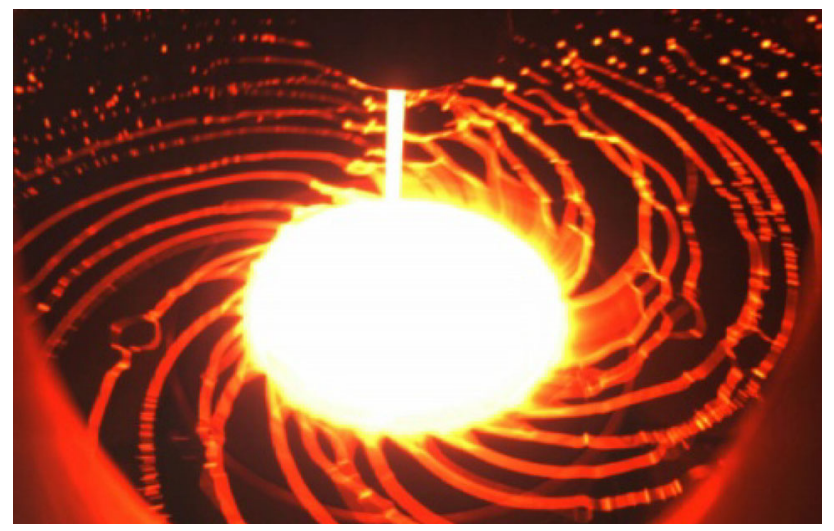

Fig. 14 A still image from a high-speed video (taken at 1,000 frame per second) of the spinning disc $(200 \mathrm{~mm}$ in diameter, spinning at $800 \mathrm{rpm}$ ) during atomization and dry granulation of a molten slag at $1,450{ }^{\circ} \mathrm{C}$ and a tapping rate of $40 \mathrm{~kg} / \mathrm{min}$

when it spreads under centrifugal forces to move towards the disc edge and then atomised there.

Figure 14 is a still image of slag atomization by the spinning disc rotating at $800 \mathrm{rpm}$ for a slag tapping rate of $40 \mathrm{~kg} / \mathrm{min}$. This figure shows the formation and breakup of the molten slag ligaments into fine droplets. Other installed video cameras and sensors in the pilot plant have provided valuable information and insight into the fast dynamic processes taking place, while the droplets are in flight, collision and circulation of granules in the cyclonic section of the unit. These observations and measurements are being used for validation of the computational fluid dynamic (CFD) model as well as optimisation of the operating procedures.

A number of parallel studies were carried out in support of process development and optimisation. These investigations covered

- Development and validation of advanced CFD models of the process as a tool for process optimisation and scale up.

- Thermodynamics and kinetics of sulphur transfer from the slag to the gas phase.

- Droplet collision with metal plates.

- Techno-economic and environmental assessment of the DSG process.

- Various plant-based measurements and heat transfer modelling.

In the following sections, some highlights from a few of these studies are presented.

\section{Process Simulation Using Computational Fluid} Dynamics

While the concept of using a spinning disc atomizer is simple, the interactions between phases can be complex and central to the successful operation of the DSG process. In this respect, the fundamental steps involved in DSG include:

i. Centrifugal spreading of molten stream of slag on the rotating disc

ii. Breaking up of the molten slag film to form ligaments at the edge of the spinning disc

iii. Breaking up of the ligaments into droplets at a short distance away from the spinning disc, by the surface tension of the slag

iv. Flight of the molten droplets and heat transfer to the gas phase

v. Collision and heat transfer between droplets/granules with reactor walls/roof

vi. Heat transfer between granules and air in the cyclone section and the packed bed reactor.

To account for the above interactions, it has been useful to develop a CFD model that links the fluid flow phenomena with the physico-chemical properties of slag (liquidus temperature, viscosity, thermal conductivity, surface tension, etc.) and physical properties of the other materials involved. In our work, the appropriate CFD modelling techniques were applied to gain a deeper understanding of the effects of process variables and reactor geometry on the performance of the DSG process under steady-state fluid flow and heat transfer. This modelling work is a key component of our strategy for process design, optimisation and scale-up. Some of the early results on simulation of free surface flow and heat transfer between molten slag and spinning disc have been published $[49,50]$. The findings from these and subsequent studies have quantified the effects of slag temperature, tapping rate and spinning speed on slag atomisation and heat transfer between phases.

In Fig. 15, the results obtained from three-dimensional (3D) CFD modelling studies on the breakup process of liquid slag and the size distribution of slag droplets are presented in comparison with experimental observations and measurements. These results are for a slag tapping rate of $2 \mathrm{~kg} / \mathrm{min}$ with other conditions (disc spinning rate, slag temperature, etc.) being similar to those used in the small pilot plant. It can be seen from Fig. 15a and $b$ that the 3D CFD model qualitatively captures the key features of ligament formation and subsequent ligament break up into droplets as observed in the experiment. It is also evident from Fig. 15c that the bimodal size distribution observed from experimental work on the pilot plant is predicted by the 3D CFD model. It is worth noting that the model results presented were obtained through modelling of ligament and droplet formation close to the rotating disc and did not cover possible collision of the droplets with the wall/roof or each other. A more detailed account of the methodology and results obtained from these simulations is provided elsewhere [49]. 
Fig. 15 Comparison of 3D CFD modelling results with the observations and measurements from a laboratory-scale DSG trial $(50 \mathrm{~mm}$ diameter disc, at 1,780 RPM, 2 kg/min slag)

[51]. a CFD simulation, b Experimental observation, c Comparison between the size distribution of slag droplets calculated with measurements

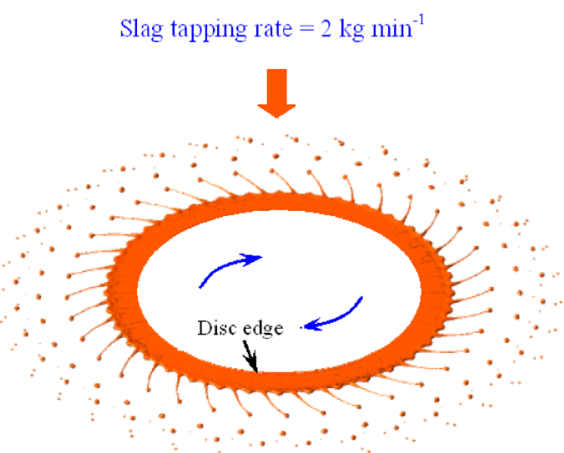

(a) CFD simulation

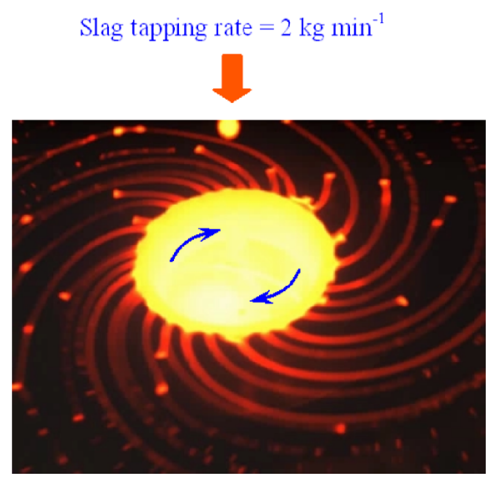

(b) Experimental observation

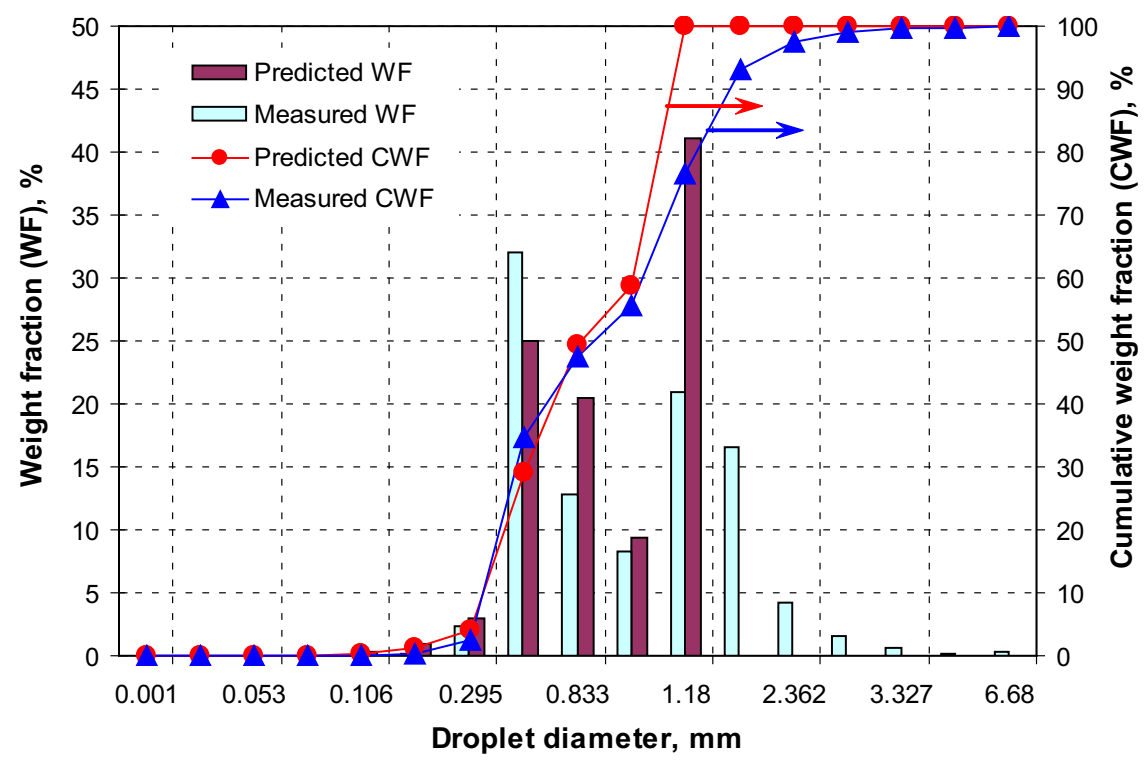

(c) Comparison between the size distribution of slag droplets calculated with measurements

\section{Sulphurous Emissions}

As indicated previously, emission of gaseous sulphur containing species during conventional water granulation could be a significant issue for some plants and there is a growing need to avoid sulphur emission to address plant hygiene and HSE requirements. The emission of sulphur during water granulation could take place via chemical reactions such as

$$
\begin{aligned}
& (\mathrm{CaS})_{\text {slag }}+\mathrm{H}_{2} \mathrm{O}(\mathrm{g})=\mathrm{H}_{2} \mathrm{~S}(\mathrm{~g})+(\mathrm{CaO})_{\text {slag }} \\
& \mathrm{H}_{2} \mathrm{~S}(\mathrm{~g})+2 \mathrm{O}_{2}(\mathrm{~g})=\mathrm{H}_{2} \mathrm{SO}_{4} \\
& \mathrm{H}_{2} \mathrm{~S}+3 / 2 \mathrm{O}_{2}(\mathrm{~g})=\mathrm{SO}_{2}(\mathrm{~g})+\mathrm{H}_{2} \mathrm{O}(\mathrm{g})
\end{aligned}
$$

which could result in the formation of undesirable hydrogen sulphide, sulphur dioxide and acid mist.

During the DSG trials, no evidence of significant sulphur loss or emission was detected. This was further investigated through analysis of published studies on the thermodynamics and kinetics of sulphur bearing ironmaking slags with gas mixtures containing water vapour or oxygen. The details of this analysis were reported elsewhere by the present authors [48, 52] and led to the conclusion that the conditions for dry granulation using air are least favourable for sulphur transfer from the slag to gaseous form. In contrast, contact of molten slag with water presents highly favourable conditions for sulphur transfer from the ironmaking slag to gas or water, in terms of both the thermodynamics and kinetics. Thus, the findings from dry granulation of slags containing up to about $0.7 \mathrm{wt} \%$ sulphur is consistent with that predicted from thermodynamics and kinetics of high temperature reactions. Furthermore, as it was pointed out earlier, dry granulated slag has a higher density than water granulated slag with identical chemical composition. The measured difference in the density of the slag samples was about a factor of two, with the water granulated slag being very porous. Such a difference in porosity and hence surface area for contacting water vapour would also contribute to the rate of desulphurisation of a unit mass of slag. 


\section{Droplet Collision with Metal Plates}

The collision of molten slag droplets with metal surfaces inside the reactor is another very important step in the DSG process. In particular, when designing a compact reactor so as to achieve recovery of high-grade heat by air one needs to manage heat transfer between molten droplets during their short flight time, plus collision with the wall and roof of the reactor. If this is not managed, slag droplets could stick to the impact area, causing buildup and the need for maintenance. Our current knowledge and understanding of the wetting, spreading and subsequent interactions (when molten slag droplet contacts solid substrates) is limited and the fundamentals of such interactions at high temperatures are not well understood. In order to develop an improved understanding of the mechanisms and governing parameters in the collision of molten slag droplets with solid surfaces, a series of droplet collision experiments was carried out under controlled laboratory conditions. In these experiments, a high-speed video camera was used to capture images of the collision sequence (wetting, spreading, recoiling and then rolling off or bouncing off) for analysis of the processes taking place as the molten droplets collide with a cold steel plate. The details of the experimental apparatus and procedures are provided elsewhere [52].

The results presented below were obtained from studying collision of single slag droplets free falling from $1.7 \mathrm{~m}$ with flat plates. A BF slag containing about $42.1 \mathrm{wt} \% \mathrm{CaO}$, $35 \% \mathrm{SiO}_{2}, 14.7 \% \mathrm{Al}_{2} \mathrm{O}_{3}, 6.1 \% \mathrm{MgO}$ and $0.44 \mathrm{~S} \%$ was used for these experiments. This slag had a liquidus temperature of about $1,400{ }^{\circ} \mathrm{C}$ and most experiments were carried out at temperatures between 1,420 and $1,580{ }^{\circ} \mathrm{C}$. Slag droplets with high velocities on collision with inclined surfaces generally exhibit a process of falling $\rightarrow$ contacting $\rightarrow$ spreading $\rightarrow$ recoiling $\rightarrow$ bouncing $\rightarrow$ rolling or tumbling, as shown in Fig. 16 [52].
Fig. 16 Sequence of still video images showing typical process of collision between a molten slag droplet and an inclined plate. Conditions: stainless steel plate, inclination angle of $30^{\circ}$, slag temperature of $1,500{ }^{\circ} \mathrm{C}$ and a free-fall height of $1.7 \mathrm{~m}$ [52]

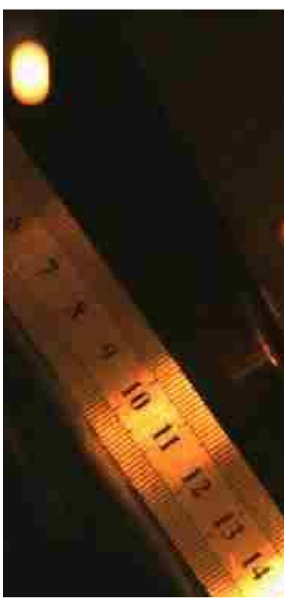

(a) Time $=-9 \mathrm{~ms}$ Falling

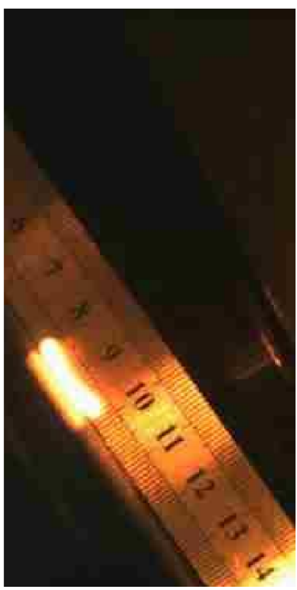

(e) Time $=21 \mathrm{~ms}$ Recoiling

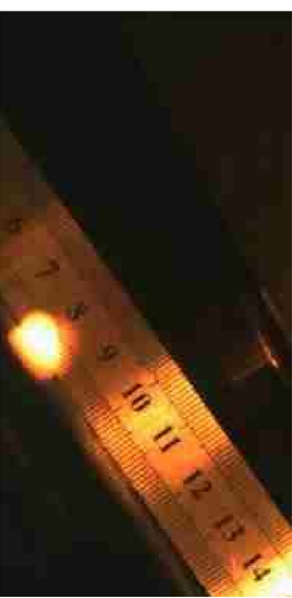

(b) Time $=0 \mathrm{~ms}$ Colliding

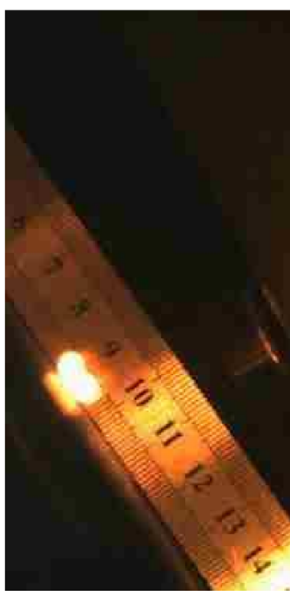

(f) Time $=41 \mathrm{~ms}$ Recoiling/bouncing

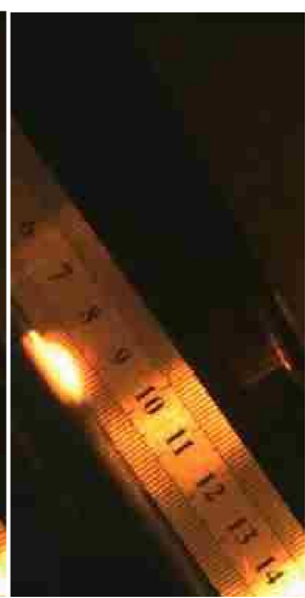

(c) Time $=1 \mathrm{~ms}$ Spreading

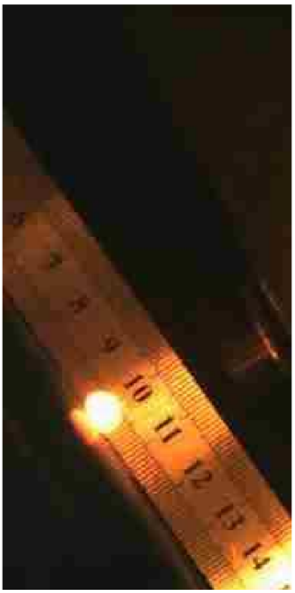

(g) Time $=81 \mathrm{~ms}$ Rolling

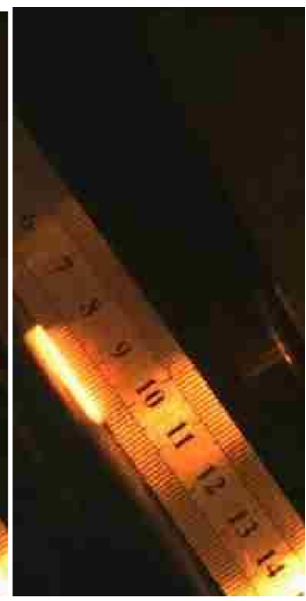

(d) Time $=3 \mathrm{~ms}$ Spreading

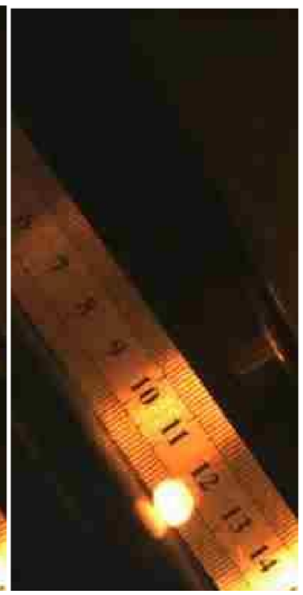

(h) Time $=131 \mathrm{~ms}$ Rolling 
The effects of variables (e.g. droplet size and temperature, the plate material, inclined angle and its surface finish) on the maximum spreading length and spreading time were measured from the images taken by a high-speed video camera. As shown in Fig. 17, the droplet size has significant effects on both the maximum spreading length as well as the spreading time before recoiling starts. Larger droplets spread more and their spreading time could increase to about $50 \mathrm{~ms}$ before recoiling starts. The maximum spreading length is about three times the original droplet diameter.

On average, the slag droplet temperature did not show a marked effect on the spreading length and time, while the plate surface condition/treatment showed strong effects. It was found that droplets colliding on the stainless steel surfaces generally spread less while they were in contact with the plate for longer time. Smooth surfaces will help to reduce the droplet spreading time.

The results obtained require further analysis before a detailed model of the observed behaviour can be developed. In the meantime, the results obtained have provided some useful data on the variations of contact time and area as droplets collide with steel surfaces (i.e. the roof and walls of the granulator). Such information has been used in the CFD model of the integrated process where heat transfer between molten slag droplets and cooling air, as well as between the droplets and steel roof, is calculated.
Environmental and Techno-Economic Analyses

Based on LCA, the avoided GHG emissions for dry granulation compared to wet granulation are 87 and $867 \mathrm{~kg}$ $\mathrm{CO}_{2}$-e/t slag compared to slow air-cooling of slag [53]. The difference between these two figures is associated with the potential saving in GHG emissions when the granulated slag replaces Portland cement. Given that approximately $0.3 \mathrm{t}$ of slag is produced per tonne of HM, the savings in GHG emissions would translate to reduction of $0.027 \mathrm{t}$ $\mathrm{CO}_{2}$-e/t-crude steel compared to wet granulation and $0.27 \mathrm{t}$ $\mathrm{CO}_{2}$-e/t-crude steel compared to slow air cooled.

Techno-economic analysis of the new integrated dry granulation process has been carried out and results indicated significant savings in both capital and operational costs compared with the water granulation process as shown in Fig. 18. The details of the information used and assumptions made for this analysis can be found elsewhere $[17,53]$.

It is worth noting that the DSG process offers a number of process credits which have potential to improve the overall process economics compared to wet granulation or no treatment (air cooled in slag pits). Compared to wet granulation, these potential credits include elimination of significant volumes water for granulation, energy consumed in slag drying, utilisation of recovered waste heat
Fig. 17 Effects of slag droplet size on: a maximum spreading length and $\mathbf{b}$ spreading time on a stainless steel surface inclined at $30^{\circ}$ (slag temperature $1,500{ }^{\circ} \mathrm{C}$ and droplets free falling about $1.7 \mathrm{~m}$ before collision [52] (a)

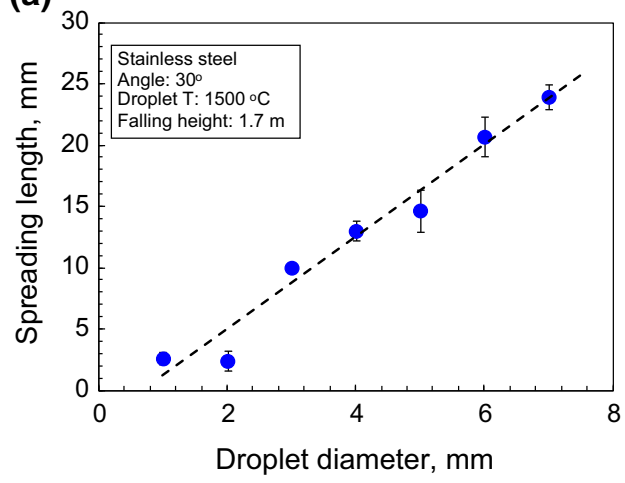

(b)

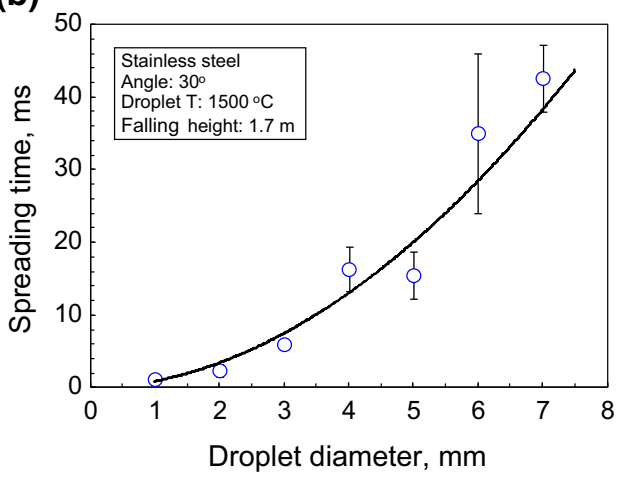

Fig. 18 Comparison of estimated capital and operating costs for the integrated dry slag granulation and heat recovery process with conventional wet granulation for a plant processing $300,000 \mathrm{t}$ of slag per year [17]
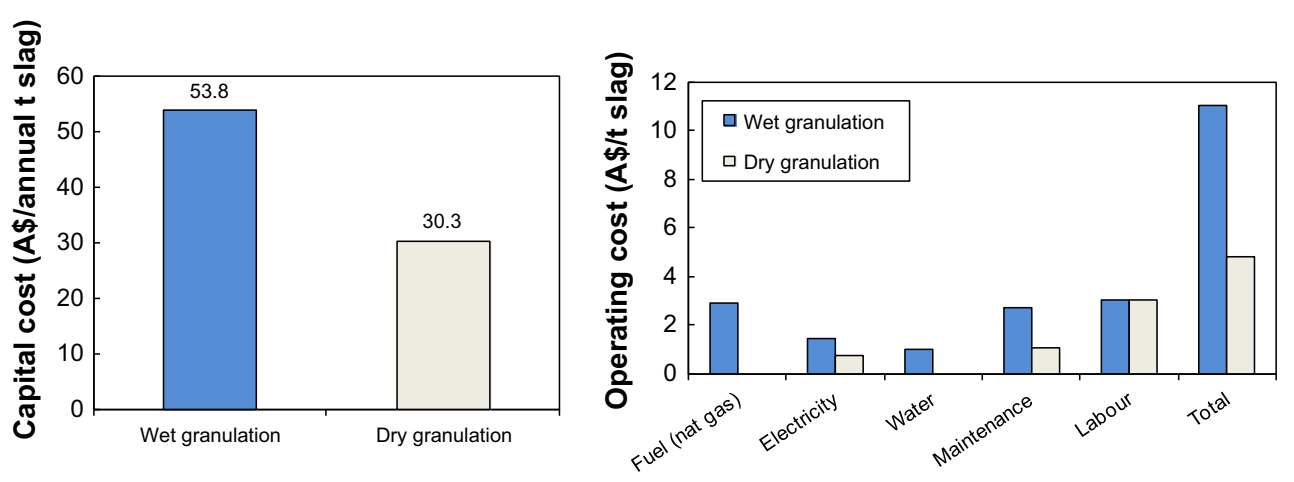
and hence avoided GHG emissions as well as any associated carbon credit. The potential credits compared to aircooling (no treatment) also included the revenue derived from selling of the granulated BF slag to Portland cement producers for use as a cement substitute, and the avoided GHG emissions and hence carbon cost associated with this substitution. These credits total to about $\$ 15$ and $\$ 60$ per tonne of slag, when DSG replaces wet granulation and aircooled slag, respectively. These figures are based on a water consumption rate of 1 tonne per tonne of slag priced at $\$ 1$ per tonne of water and carbon credit of $\$ 23$ per tonne of $\mathrm{CO}_{2}$. Further details and breakdown of these cost estimates are provided elsewhere $[17,53]$.

\section{Future Directions and Concluding Remarks}

The Australian Steel Industry $\mathrm{CO}_{2}$ Breakthrough Program has identified twelve process applications where biomassderived fuels and reductants can contribute to net $\mathrm{CO}_{2}$ reductions in the integrated (BF-BOF) and mini-mill (EAF) steelmaking routes. $R \& D$ has been progressing for each of the applications and several are either ready for industrial trial or have already been tested. This technical work has been supported by studies of biomass and charcoal supply and techno-economic evaluations.

For the integrated BF-BOF route, the use of renewable biomass-derived chars in ironmaking and steelmaking has the potential to decrease net $\mathrm{CO}_{2}$ emissions by $31-57 \%$ directly, and more under full life-cycle considerations. The potential in the EAF route is less, at around 8-12\%, because its energy principally comes from the electricity grid and therefore depends on emissions in that sector.

Australia currently has a very small charcoal-making capability that supports silicon manufacture and the barbecue fuel market. However, the potential market for charcoal within the steel industry is around $1 \mathrm{Mt} / \mathrm{year}$, if the optimised products shown in Table 3 can be provided at prices competitive with their fossil-based equivalents. The economics of charcoal supply can be optimised by use of clean nonprime feed materials such as forest harvest residues, rather than woodchips or sawlogs. The sale or utilisation of pyrolysis co-products is also important to the economics. Use of new energy and resource efficient pyrolysis technology would make a significant difference in the overall economics of charcoal, however, such emerging technologies need to be demonstrated at an industrial scale.

Surveys conducted as part of this project have indicated that sufficient feed materials already exist in South Eastern Australia to satisfy a large part of the potential demand from the steel industry. These principally consist of plantation forest harvest residues and waste wood from domestic and industrial demolition.
For the steel industry, the use of renewable fuels and reductants from sustainable sources is a low capital, relatively low technical risk option for the introduction of deep cuts in net $\mathrm{CO}_{2}$ emissions. With the introduction of carbon price, the use of renewable carbon and designer chars would become economically more attractive compared to metallurgical coal and coke. A current hurdle is the development of an Australian biomass-charcoal supply industry, not only to support the potential steel industry applications but also to feed industrial trials of charcoal in the larger applications. Other parties associated with the supply of biomass and/or pyrolysis technologies outside of the steel industry are endeavouring to develop such a charcoal supply industry.

Decreasing demand for newsprint may also free some existing resources. Nonetheless, there is a significant challenge ahead to initiate a distributed charcoal-producing industry, under stringent environmental controls, and with a need to capture and utilise the liquid and gaseous coproducts for both greenhouse and economic reasons. Australia is well placed amongst a limited number of countries due to its capability for sustainable forestry to cultivate a charcoal industry for domestic and export markets. It already has an industry exporting DBF pellets to Europe, and charcoal is a globally traded commodity.

Waste heat recovery from molten BF slag and its utilisation in various applications around the steel plant could result in significant saving in energy usage and hence GHG emission. The dry granulated BF slag was found to be highly glassy $(\sim 98 \%)$ and have very good cementitious properties. Thus dry granulated slag could be used as a partial substitute for Portland cement with the added advantage of having lower GHG emissions associated with it.

The ongoing work on DSG process development will focus on issues relating to scale up of the reactor to an industrial scale (up to $1 \mathrm{t} / \mathrm{min}$ ) through optimisation of design and operating parameters. This will involve fullscale trials at a metallurgical plant with access to a large volume of molten slag. This will allow continuous operation of the process for extended periods so that steady-state conditions can be reached and the off-gas temperature approaches the targeted theoretical values based on heat balance/transfer calculations. The full integration of a moving packed bed with the dry granulation unit also needs to be demonstrated. These trials will also demonstrate the expected long life of the spinning disc under plant operating conditions, at steady state. Other practical issues that will be addressed through the trials will be the means of delivering a steady stream of molten slag at a controlled flow rate. The granulated slag product could then be run through a cement production plant to demonstrate the product quality and performance as a substitute for Portland cement. 
Through combining the carbon credits for waste heat recovery from molten slag and production of "green cement" from dry granulated BF slag, then the total reduction in $\mathrm{GHG}$ emissions for integrated $\mathrm{BF}-\mathrm{BOF}$ route improves by a further $10 \%$ (i.e. $41-67 \%$ ).

Acknowledgments The work reported in this paper has been supported by CSIRO since 2002 and co-sponsored by BlueScope Steel and Arrium (OneSteel) since July 2007. The Centre for Sustainable Resource Processing (CSRP) was also a co-sponsor of the project between 2006 and 2009. The authors gratefully acknowledge contributions by other members of the project team, in particular, Drs Benny Kuan, Peter Witt, Liming Lu, Harold Rogers, Habib Zughbi, Paul Koltun and David Langberg as well as Messrs Jason Donnelly, Michael Nagle, Bernie Washington, Steve Sanetsis, Dylan Marley and Justen Bremmell.

\section{References}

1. WSA (2013) Steel's contribution to a low carbon future; Worldsteel position paper, World Steel Association, March. http://www.worldsteel.org/publications/position-papers/Steel-scontribution-to-a-low-carbon-future.html. Accessed June 2014

2. WSA (2014), ' $\mathrm{CO}_{2}$ emissions data collection', World Steel Association. http://www.worldsteel.org/steel-by-topic/climatechange/data-collection.html. Accessed June 2014

3. Fruehan RJ, Fortini O, Paxton HW, Brindle R (2000) Theoretical minimum energies to produce steel for selected conditions. Consultant report for the US Department of Energy, Office of Industrial Technologies, Washington, p 33

4. Barati M, Esfahani S, Utigard T (2011) Energy recovery from high temperature slags. Energy 36:5440-5449

5. Birat J-P, Hanrot F (2005) ULCOS-European steelmakers' efforts to reduce greenhouse gas emissions. In: 5th European Coke and Ironmaking Congress, Swedish Steel Producers' Association, Stockholm, June, We7: 4-1-4-12

6. ULCOS (2014). http://www.ulcos.org/en/index.php. Accessed June 2014

7. Birat J-P (2011) $\mathrm{CO}_{2}$-lean steelmaking: ULCOS, other international programs and emerging concepts. EECR-METEC InSteelCon 2011, Dusseldorf, June 2011, Session 1, CD-ROM

8. COURSE50 (2014). http://www.jisf.or.jp/course50/outline/ index_en.html Accessed Jan 2014

9. Miwa T, Okuda $\mathrm{H}$ (2010) $\mathrm{CO}_{2}$ ultimate reduction in steelmaking process by innovative technology for cool earth 50. J Jpn Inst Energy 86:28-35

10. Tonomura S (2013) Outline of Course 50. Energy Procedia 37:7160-7167

11. Takeda T, Anyashiki T, Sato T, Oyama N, Watakabe S, Sato M (2011) Recent developments in mid- and long-term $\mathrm{CO}_{2}$ mitigation projects in ironmaking. Steel Res Int 82:512-520

12. Jahanshahi S, Deev A, Haque N, Lu L, Mathieson JG, Norgate TE, Pan Y, Ridgeway P, Rogers H, Somerville MA, Xie D, Zulli $P$ (2014) Current status and future direction of low emission integrated steelmaking process. Celebrating the Megascale: an EPD Symposium in Honor of David G. C. Robertson, TMS, San Diego, 303-316 Feb 2014

13. Mathieson JG, Rogers H, Somerville M, Ridgeway P, Jahanshahi $S$ (2011a) Use of biomass in the iron and steel industry-an Australian perspective, EECR-METEC InSteelCon, Dusseldorf, June, paper 252, CD-ROM

14. Hasanbeigi M, Arens L Price (2014) Alternative emerging ironmaking technologies for energy-efficiency and carbon dioxide emissions reduction: a technical review. Renew Sust Energy Rev 33:645-658

15. Norgate T, Haque N, Somerville M, Jahanshahi S (2012) Biomass as a source of renewable carbon for iron and steelmaking. ISIJ Intern 52(8):1472-1481

16. Xie D, Jahanshahi S (2008) Waste heat recovery from molten slags. In: International Congress on Steel (ICS2008), Gifu, Japan, 6-8 October

17. Norgate T, Xie D, Jahanshahi S (2012b) Economic and environmental evaluation of slag dry granulation. In: SCANMET IV - 4th International Conference on Process Development in Iron and Steelmaking; 10-13 June; Lulea, Sweden. Lulea, Sweden: SCANMET Organiser, CD-ROM

18. Haque N, Somerville M, Jahanshahi S, Mathieson JG, Ridgeway P (2008) Survey of sustainable biomass resources for the iron and steel industry. 2nd Annual Conference, Centre for Sustainable Resource Processing (CSRP'08), Brisbane

19. Vassilev SV, Baxter D, Andersen LK, Vassileva CG (2010) An overview of the chemical composition of biomass. Fuel 89:913-933

20. Fung P (2008) Review of pyrolysis technology. Unpublished report. Evergreen Energy Australia Pty Ltd, October

21. Somerville MA, Bremmell JB (2014) Characterisation of products from the pyrolysis of South Australian Radiata pine. In: 6th Annual High Temperature Symposium 2014, Swinburne University of Technology, 103-110

22. Emrich W (1985) Handbook of charcoal making: the traditional and industrial method, vol 7., Series E: Energy From BiomassCommission of the European Communities. D. Reidel Publishing Company, Dordrecht

23. Stucley C (2001) Integrated tree processing of mallee eucalypts. RRIDC Publication No 01/160, Barton

24. Deev A, Jahanshahi S (2012) Development of a pyrolysis technology to produce large quantities of charcoal for the iron and steel industry. In: 6th International Congress on the Science and Technology of Ironmaking, Rio de Janeiro, 1132-1142

25. Deev AD (2012) Apparatus and process for continuous carbonisation of wood chips or wastes and other charring organic materials for charcoal production, International Patent Application WO 2012174587, A1

26. Stafford OF (1921) Destructive Distillation Process. US patent 1, 380, 262.

27. Mathieson JG, Rogers H, Somerville MA, Jahanshahi S, Ridgeway P (2011b) Potential for the use of biomass in the iron and steel industry. In: Chemeca 2011, paper 252, September, CDROM

28. Mathieson JG, Rogers H, Somerville M, Jahanshahi S (2012) Reducing $\mathrm{CO}_{2}$ emissions using charcoal as a blast furnace tuyere injectant. ISIJ Intern 52:1489-1496

29. Mathieson JG, Norgate T, Jahanshahi S, Somerville MA, Haque N, Deev A, Ridgeway P, Zulli P (2012b) The potential for charcoal to reduce net greenhouse emissions from the Australian steel industry. In: 6th International Congress on the Science and Technology of Ironmaking, Rio de Janeiro, October: 602-613

30. Somerville MA, Mathieson JG, Ridgeway P (2012) Overcoming problems of using charcoal as a substitute for coal and coke in iron and steelmaking operations. In: 6th International Congress on the Science and Technology of Iron making, Rio de Janeiro, October, Brazil, CD-ROM

31. Demeyer A, Voundi Nikana JC, Verloo MG (2011) Charcterisation of wood as and influence on soil properties and nutrient uptake: an overview. Bioresour Technol 77:287-295

32. Ulery AL, Graham RC, Amrhein C (1993) Wood-ash composition and soil $\mathrm{pH}$ following intense burning. Soil Sci 156:125-138

33. Somerville MA, Davies M, Mathieson JG, Ridgeway P, Jahanshahi S (2011). Addition of renewable carbon to liquid steel: 
Plant trials at One Steel Sydney Steel Mill. CHEMECA 2011, Sydney, September Paper 223, CD

34. Lu L, Adam M, Somerville M, Hapugoda S, Jahanshahi S, Mathieson JG (2012) Iron ore sintering with charcoal. In: 6th International Congress on the Science and Technology of Ironmaking, Rio de Janeiro, 1121-1131

35. Ando J, Nakahara T, Onous H, Ichimura S, Kondo M (1985) Development of slag blast granulation plant characterised by innovation of the slag treatment method, heat recovery and recovery of slag as resources. Mitsubishi Heavy Ind Tech Rev 22(2):136-142

36. Featherstone WB (1998) Slag treatment improvement by dry granulation. Iron and Steel Engineer, July:42

37. Macauley D (1996) Slag treatment-time for an improvement. Steel Times International: S15-16

38. Pickering S, Hay N, Roylance T, Thomas G (1985) New process for dry granulation and heat recovery from molten blast furnace slag. Ironmak Steelmak 12(1):14-21

39. Yoshida H, Nara Y, Nakatani G, Anzai T, Sato H (1984) The technology of slag heat recovery at NKK, Technical Research Center, NKK, Japan, 1984, paper 21

40. Yoshinaga M, Fujii K, Shigematsu T, Nakata T (1982) Dry granulation and solidification of molten blast furnace slag. Trans ISIJ 22:823-829

41. Rodd L, Koehler T, Walker C, Voermann N (2010). Economics of slag heat recovery from ferronickel slags. COM 2010 Conference of Metallurgists, Vancouver, October

42. Kappes H, Paul Wurth's contribution to an energy optimized iron making technology. In: Proceeding of METEC InSteelCon, Düsseldorf, 2011

43. Motz H, Ehrenberg A, Mudersbach D (2013) Dry solidification with heat recovery of ferrous slag. In: 3rd Proceedings of Int. Slag Valorisation Symposium, 19-20 March 2013, Leuven, Belgium: $37-55$

44. Mizuochi T, Akiyama T, Shimada T, Kasai E, Yagi J (2001) Feasibility of rotary cup atomizer for slag granulation. ISIJ Intern 41(12):1423-1428

45. Kashiwaya Y, In-Nami Y, Akiyama T (2010) Mechanism of the formation of slag particles by the rotary cylinder atomization. ISIJ Intern 50(9): 1252-1258

46. Liu L, Yu Q, Qin Q (2011) System for recovering waste heat from high temperature molten blast furnace slag. Energy Technol: $85-93$

47. Xie D, Jahanshahi S, Norgate T (2010) Dry granulation to provide sustainable option for slag treatment. Sustainable Mining
Conference, Kalgoorlie, Western Australia, August, (AusIMM): 22-28

48. Jahanshahi S, Xie D, Pan Y, Ridgeway P, Mathieson JG (2011) Dry slag granulation with integrated heat recovery. 1st International conference on energy efficiency and $\mathrm{CO}_{2}$ reduction in the steel industry (EECR Steel 2011) - incorporated in METEC InSteelCon 2011, 27 June-1 July, Dusseldorf, Germany, pp. Session 13, (7p)

49. Pan Y, Witt PJ, Xie D (2010) CFD simulation of free surface flow and heat transfer of liquid slag on a spinning disc for a novel dry slag granulation process. Prog Comput Fluid Dyn 5(6):292-299

50. Pan Y, Witt PJ, Kuan B, Xie D (2014) CFD modelling of the effect of operating parameters on the spreading of liquids on a spinning disc. J Comput Multiph Flow 6(1):49-64

51. Pan Y, Witt PJ, Kuan B, Xie D (2011) CFD simulation of slag droplet formation by a spinning disc in dry slag granulation processes. In: 8th International conference on CFD in Oil \& Gas, Metallurgical and Process Industries, 21-23 June, SINTEF/ NTNU, Trondheim Norway. Paper 152 (8p)

52. Jahanshahi S, Pan Y, Xie D (2012) Some fundamental aspects of dry slag granulation process. In: 9th International Conference on Molten Slags, Fluxes and Salts (Molten12), Beijing, 27-31 May 2012, CD-ROM

53. Norgate T, Xie D, Jahanshahi S (2012c) Technical and economic evaluation of dry slag granulation, AISTech 2012, Atlanta, 7-10 May 2012: 35-46

54. Ng KW, Giroux L, MacPhee T, Todoschuk T (2012) Incorporation of charcoal in coking coal blend-a study of the effects on carbonization conditions and coke quality. In: AISTech 2012: Proceedings of the iron \& steel technology conference, Atlanta, 7-10 May 2012: 225-236

55. Gonclaves LJ, de Oliveira VM, da Silva FR (2012) Consumption of small charcoal in blast furnace 2 of Aperam South America, In: 6th International Congress on the Science and Technology of Ironmaking, Rio de Janeiro, Oct 1765-1776

56. Babich A, Senk D, Fernandez M (2010) Charcoal behaviour by its injection into the modern blast furnace. ISIJ Intern 50:81-88

57. Usui T, Konishi H, Ichikawa K, Ono H (2012) Preparation and reduction behaviour of carbon composite pellets using semicharcoal. In: 6th International Congress on the Science and Technology of Ironmaking, Rio de Janeiro, October: 698-709

58. Wibberley L, Nunn J, Scaife P, Zivlas A, Andrews L, Coomber B, Dickson R, Gardner D, Cowie A (2001) Large scale use of forest biomass for iron and steelmaking. NSW Government Sustainable Energy Research Development Fund (SERDF) Report by BHP Minerals Technology and NSW State Forests 